\title{
Electrochemical Synthesis of Poly(3,4-ethylenedioxythiophene) Film Having Dot Structures for Diffraction Grating
}

\author{
Naoto Eguchi, Hiromasa Goto*
}

Department of Materials Science, Faculty of Pure and Applied Sciences, University of Tsukuba, Tsukuba, Ibaraki 305-8573, Japan.

E-mail: gotoh@ims.tsukuba.ac.jp

KEYWORDS: liquid crystal imprinting; hydroxypropyl cellulose; electrochemical polymerization; grating; electrochromism

\begin{abstract}
Poly(3,4-ethylenedioxythiophene) (PEDOT) dot micro-/nanostructures are synthesized by electrochemical polymerization in a concentrated hydroxypropyl cellulose (HPC) liquid crystal electrolyte solution. Surface observations by scanning electron microscopy and atomic force microscopy reveal micro-/nanostructures having hemisphere-like dots on the surface of the PEDOT film, which causes light diffraction at ultraviolet and visible light wavelengths. The size of the dots depends on the concentration of the HPC electrolyte solution, decreasing with increasing the HPC concentration. Electrochemical oxidation and reduction causes changes in the color of the PEDOT film and the diffracted light. Moreover, Au coating on the surface of the PEDOT film enhances the diffracted light reflection intensity by more than tenfold compared to the non-coated PEDOT film.
\end{abstract}

1. Introduction

The investigations of micro-/nano-structured surfaces are of great interest in the field of science and technology because materials with controlled surface micro-/nanostructures can be used in various applications such as super water repellents, plasmon resonance, enhancement of mechanical adhesions, and anti-reflection. ${ }^{1-4}$ Recently, research in this field has focused on the micro-/nanostructures of $\pi$-conjugated polymers because the intrinsic property of the $\pi$ conjugated system can be induced by controlling the micro-/nanostructures, resulting in enhanced performance in terms of energy efficiency of solar cells, super-capacitors, thermal conductivity, and energy storage. ${ }^{5-13}$

In this context, poly(3,4-ethylenedioxythiophene) (PEDOT) is regarded as one of the most attractive $\pi$-conjugated polymers because of its high conductivity, air stability, chemical stability, and high optical transparency at the oxidized state.

Generally, PEDOT can be synthesized by chemical polymerization, electrochemical polymerization, interfacial polymerization, or chemical vapor deposition. The fabrication of 
chemically synthesized micro-/nano-structured PEDOT in the form of spheres, rods, tubes, and fibers has been attempted by using template or template-free methods. ${ }^{14-19}$ For example, Xinyu Zhang et al. synthesized PEDOT nanotubes by chemical polymerization in the presence of a surfactant. ${ }^{20}$ As a result, microns long PEDOT nanotubes were obtained. Meanwhile, Yinan Zhang et al. synthesized PEDOT microspheres by ultrasonic spray polymerization. ${ }^{21}$ In this template-free method, ultrasonic nebulized microdroplets of 3,4-ethylenedioxythiophene (EDOT) and oxidant pass through a heated tube, affording PEDOT microspheres.

Electrochemical polymerization is also a convenient method to produce conductive polymers. Several studies on the electrochemical synthesis of PEDOT micro-/nanostructures by using various methods have been reported. ${ }^{22-29}$ Thus, Rui Xial et al. electrochemically synthesized PEDOT nanotubes in a porous alumina template and investigated systematically the effects of applied potential, monomer concentration, and temperature. ${ }^{30}$ Meanwhile, David K. Taggart et al. electrochemically synthesized PEDOT nanowires and thin films using a lithographically patterned template, obtaining ultra-long PEDOT nanowires with high Seebeck coefficient and conductivity. ${ }^{31}$

One of the advantages of electrochemical polymerization is that conductive polymers deposit directly at film state on the surface of an electrode. Generally, conductive polymers are insoluble and infusible unless an alkyl chain is introduced. This renders the dissolution of non-substituted conductive polymers in organic solvents and film preparation hard. Unfortunately, conductive polymers bearing an alkyl side chain tend to show low conductivity compared with unsubstituted conductive polymer. Note worthily, electrochemical polymerization directly affords conductive polymer films from unsubstituted monomers.

The electrochemical polymerization to produce conductive polymers in various liquid crystals such as 4-cyano-4'-hexylbiphenyl (6CB) and hydroxypropyl cellulose (HPC) solution has been previously developed. In this method, the liquid crystal is used as an electrolyte solution and soft template. Kawabata et al. performed the electrochemical polymerization of various monomers in cholesteric liquid crystal. ${ }^{32}$ The optical and scanning electron microscope observations of the obtained polymer films showed a liquid crystal-like texture, suggesting that the transcription of liquid crystal order occurred. The electrochemical polymerization of EDOT-alt-fluorene monomer in HPC liquid crystal was also attempted. ${ }^{33}$ HPC is a derivative of cellulose that is abundant in nature. It is known that concentrated aqueous or organic solutions of HPC show lyotropic cholesteric liquid crystal (CLC) behavior. ${ }^{34,35}$ Cellulose and its derivatives have been widely used as templates for producing optical materials because of their unique optical property, environmental friendly nature, and low cost. ${ }^{36,37}$ Polymer films synthesized in HPC liquid crystal show fingerprint texture and optical activity, which is consistent with the transcription of CLC helical order. Therefore, electrochemical polymerization in a liquid crystal can be envisaged as a useful and facile template method to produce micro-/nano-structured polymers.

Herein, we report the electrochemical polymerization of EDOT in a HPC liquid crystal. As a result, micro-/nano-ordered dot-like structures of PEDOT are produced on the surface of the film. It is considered that the dot-like structures are derived from transcription of fingerprint texture and deformation of polygonal texture of CLC. To the best of our knowledge, this is the first report on the synthesis of a PEDOT having such structures using HPC as a template by electrochemical polymerization. The dots are uniform in size and irregular in periodicity, and the dot size depends on the concentration of HPC liquid crystal. The PEDOT film prepared in HPC liquid crystal shows diffraction grating function due to the convex-concave surface structure. Diffraction grating consisting of liquid crystal has been paid attention and studied such as 
homeotropic aligned CLC, polymer stabilized CLC and holographic polymer-dispersed liquid crystal. ${ }^{38-46}$ Furthermore, conductive polymers such as PEDOT can be changed its optical properties dynamically between neutral state and oxidized or reduced state by electricity. Therefore, diffraction grating consisted with conductive polymers has potential for lightness, flexible and electrically adjustable optical gratings. electrochemical oxidation and reduction of the PEDOT film changes not only the film color, but also the diffracted light color due to the change of light absorption. This method using self-assembled hydroxypropyl cellulose liquid crystal offers a new approach to fabricate low-cost bottom-up-type micro-/nanostructures of conductive polymers for optical applications and the development of functional surface materials.

\section{Experimental Section}

\subsection{Chemicals}

HPC was obtained from Wako Pure Chemical Industries, Ltd (Tokyo) and was used as supplied. The viscosity of the HPC is $2.0-2.9 \mathrm{mPa} \cdot \mathrm{s}\left(2 \%, 20^{\circ} \mathrm{C}\right)$. Therefore, the molecular weight of the hydroxypropyl cellulose is approximately $40,000 \mathrm{~g} / \mathrm{mol}$. EDOT and tetrabutylammonium perchlorate (TBAP) were purchased from Tokyo Chemical Industries, Ltd (TCI, Tokyo) and were used as supplied. $N, N$-Dimethylformamide (DMF) was obtained from Nacalai Tesque, Inc (Kyoto) and was used as supplied.

\subsection{Electrochemical Polymerization}

The electrochemical polymerization of EDOT was conducted in a mixed HPC/DMF solution (Scheme 1). The HPC/DMF solution contained $1 \mathrm{wt} \%$ TBAP as a supporting salt. The electrolyte solution components, helical pitch of HPC cholesteric liquid crystal observed by polarizing optical microscope (POM) and polymerization conditions are summarized in Table 1. TBAP and EDOT were dissolved in DMF and mixed well. Then, HPC was added to the solution and allowed to stand for at least one week to form a homogeneous solution. The HPC electrolyte solution was pasted on an indium tin oxide (ITO) glass with a polytetrafluoroethylene spacer (200 $\mu \mathrm{m}$ thick) and was sandwiched with another ITO glass. The ITO glass cell was left for one day to release the shear stress and stabilize the liquid crystal phase. Then, a voltage of $3.2 \mathrm{~V}$ was applied to the cell for $30 \mathrm{~min}$. The EDOT monomer was oxidized at the surface of the anode, and PEDOT was deposited on the surface of the ITO glass in a film state. The PEDOT film deposited onto the ITO glass was washed with distilled water and acetone to remove unreacted monomer, residual HPC, and TBAP. The Fourier Transform infrared (FT-IR) spectra of EDOT and PEDOT film are shown in Figure S1.

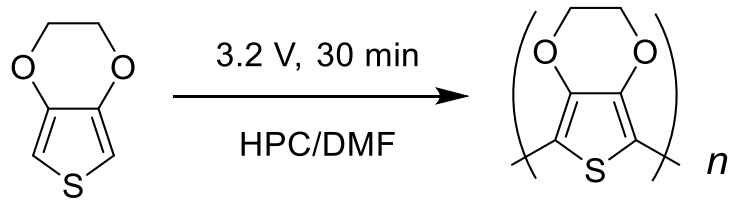

Scheme 1. Electrochemical polymerization of 3,4-ethyelenedioxythiophene (EDOT) in hydroxypropyl cellulose (HPC)/N,N-dimethylformamide (DMF) solution. 
Table 1. Electrolyte solution components and polymerization conditions.

\begin{tabular}{llllllll}
\hline Entry & $\mathrm{Wt}^{\mathrm{a}}$ & $\begin{array}{l}\mathrm{HPC} \\
(\mathrm{mg})\end{array}$ & $\begin{array}{l}\mathrm{DMF} \\
(\mu \mathrm{L})\end{array}$ & $\begin{array}{l}\text { TBAP } \\
(\mathrm{mg})\end{array}$ & $\begin{array}{l}\text { EDOT } \\
(\mu \mathrm{L})\end{array}$ & $\begin{array}{l}\text { Voltages } \\
(\mathrm{V})\end{array}$ & $\begin{array}{l}\text { Time } \\
(\mathrm{min})\end{array}$ \\
\hline PEDOT_HPC_54 & 54.0 & 491.0 & 400.0 & 14.0 & 20.0 & 3.2 & 30 \\
PEDOT_HPC_58 & 58.0 & 577.0 & 400.0 & 14.0 & 20.0 & 3.2 & 30 \\
PEDOT_HPC_62 & 62.0 & 682.0 & 400.0 & 14.0 & 20.0 & 3.2 & 30 \\
PEDOT_HPC_63 & 63.0 & 700.0 & 400.0 & 14.0 & 20.0 & 3.2 & 30 \\
PEDOT_HPC_66 & 66.0 & 812.0 & 400.0 & 14.0 & 20.0 & 3.2 & 30 \\
\hline
\end{tabular}

a Weight $\%$ of hydroxypropyl cellulose

\subsection{Characterization}

Polarizing optical microscopy (POM) observations was performed using an ECLIPS LV 100 high-resolution polarizing microscope (Nikon, Tokyo). Scanning electron microscopy (SEM) was performed with a JSM-7000F (Hitachi, Tokyo) device. Atomic force microscopy (AFM) was performed using an S-image (Hitachi, Tokyo) instrument. FT-IR absorption spectroscopy was conducted with an FT-IR 4600 (JASCO, Tokyo) instrument using the $\mathrm{KBr}$ method. The spectra were recorded in the range $400-4000 \mathrm{~cm}^{-1}$ with a resolution of $4 \mathrm{~cm}^{-1}$. UV-vis absorption spectroscopy was conducted using a V-630 (JASCO, Tokyo) spectroscope. All UVvis absorption spectra measurements were conducted at $1.0 \mathrm{~nm}$ bandwidth, $400 \mathrm{~nm} / \mathrm{min}$ scan rate, and $0.5 \mathrm{~nm}$ data interval. Cyclic voltammetry and chronoamperometry were conducted on a AAUTOLAB TYPE III (ECO Chemie, Kanaalweg) instrument. All potentials were defined against $\mathrm{Ag} / \mathrm{Ag}^{+}$reference electrode. Reflection spectroscopy measurements were performed on an ARMN-735 (JASCO) equipment. All reflection spectra measurements were conducted at 5.0 $\mathrm{nm}$ bandwidth, $1000 \mathrm{~nm} / \mathrm{min}$ scan rate, and $1.0 \mathrm{~nm}$ data interval. Optical microscope image analysis was performed by ImageJ software. Au sputtering was conducted by using a MSP-1 magnetron sputter (Vacuum Device, Japan). The thickness of Au coating was measured by using a Dektak 3ST (Ulvac, Japan).

3. Results and Discussion

3.1. Optical Microscopy

Optical microscopy and POM observations were performed on an electrolyte solution and the PEDOT_HPC_60 film. Figure 1a shows the POM image of the HPC electrolyte solution containing the EDOT monomer. The optical texture resembles the polygonal texture of a CLC, which is consistent with the previously reported result. ${ }^{47,48} \mathrm{POM}$ observation of the same region with sensitive color plate suggests that the molecule aligns circularly in region A and radially in region B (Figure 1b). Schematic illustrations corresponding to regions A and B are shown in Figure 1(c, d). 


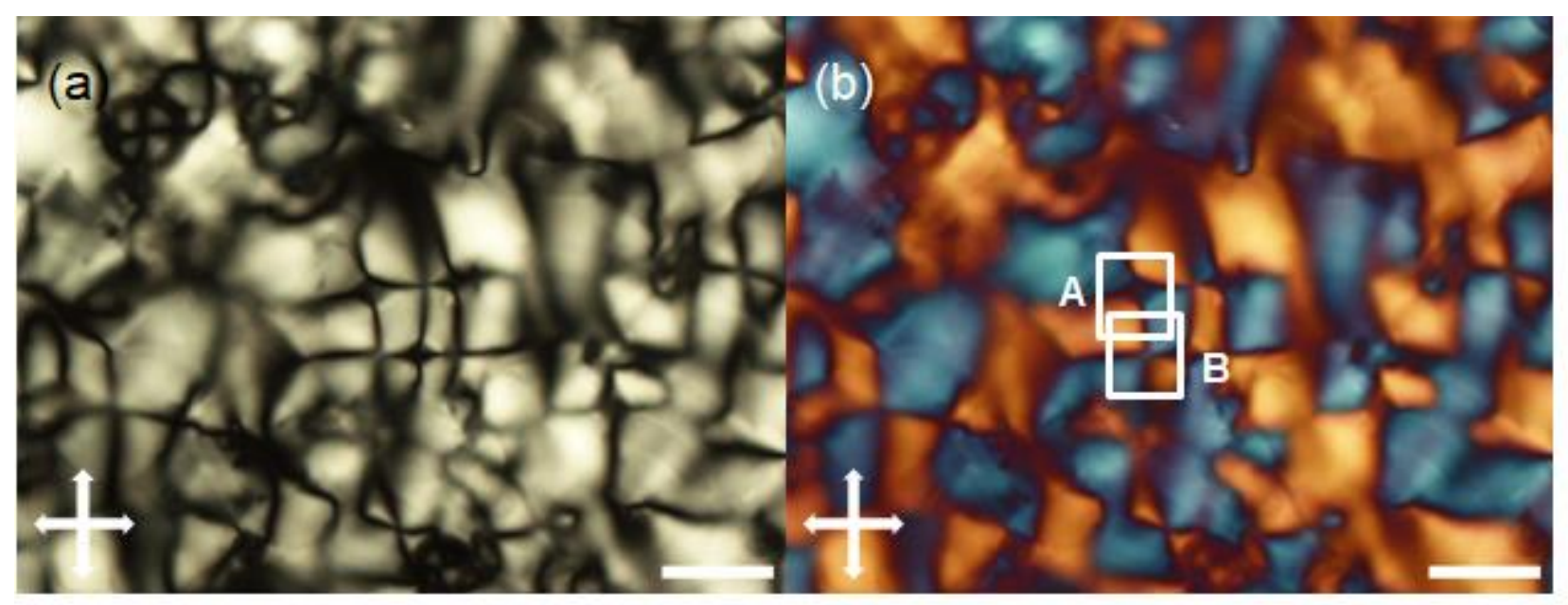

(c)

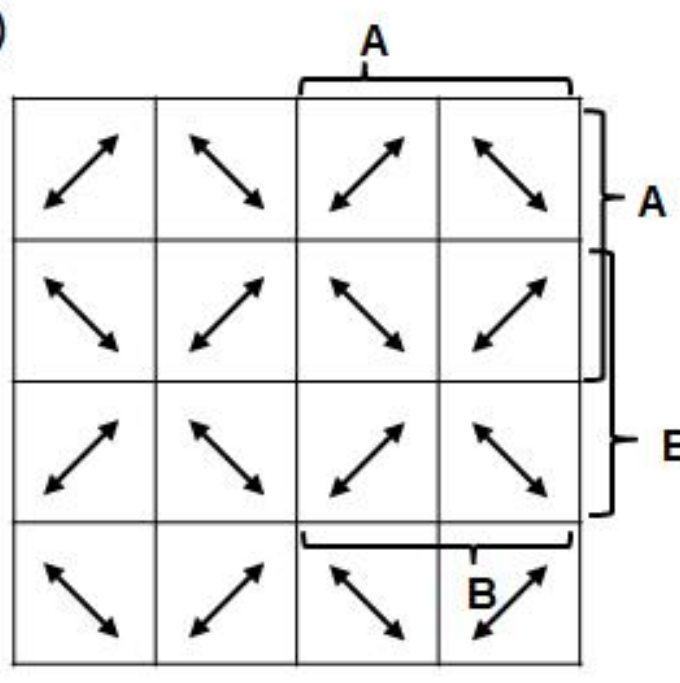

(d)

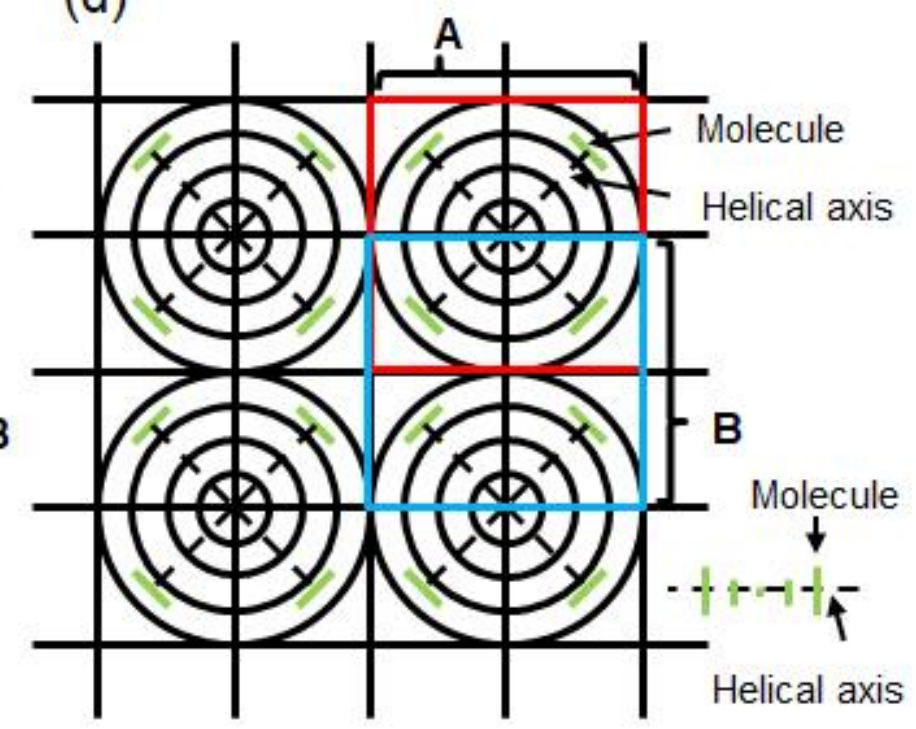

Figure 1. Polarized optical microscope image of HPC/DMF electrolyte solution containing EDOT monomer (a). POM image with sensitive color plate (b). All scale bars are $50 \mu \mathrm{m}$. Schematic illustration of regions A and B (c, d). Arrows in (c) indicate the direction of molecular orientation. Dashed lines and green solid lines correspond to the helical axis and the molecule, respectively (d).

Figure 2(a, b) show the optical microscope and POM images of the PEDOT_HPC_63 film. The optical microscope image reveals that many dots almost uniform in size and irregular in periodicity were fabricated. Figure $2 \mathrm{~b}$ shows a POM image corresponding to the same region depicted in Figure 2a. Exposure time of POM observation was 6-8 seconds for brightening the image. Therefore, background (= PEDOT film) of POM image is bright. The dots show a crossshadow pattern when viewed under cross polarizer, suggesting that the PEDOT is radially aligned. Figure 2c displays a photograph of the normal appearance of the PEDOT_HPC film showing the deep blue color which is intrinsic color of PEDOT at the oxidized state. Finally, Figure 2d shows the same PEDOT_HPC film displaying an iridescent color under oblique white light, which is attributed to the presence of periodic dots on the surface of the PEDOT_HPC film. 

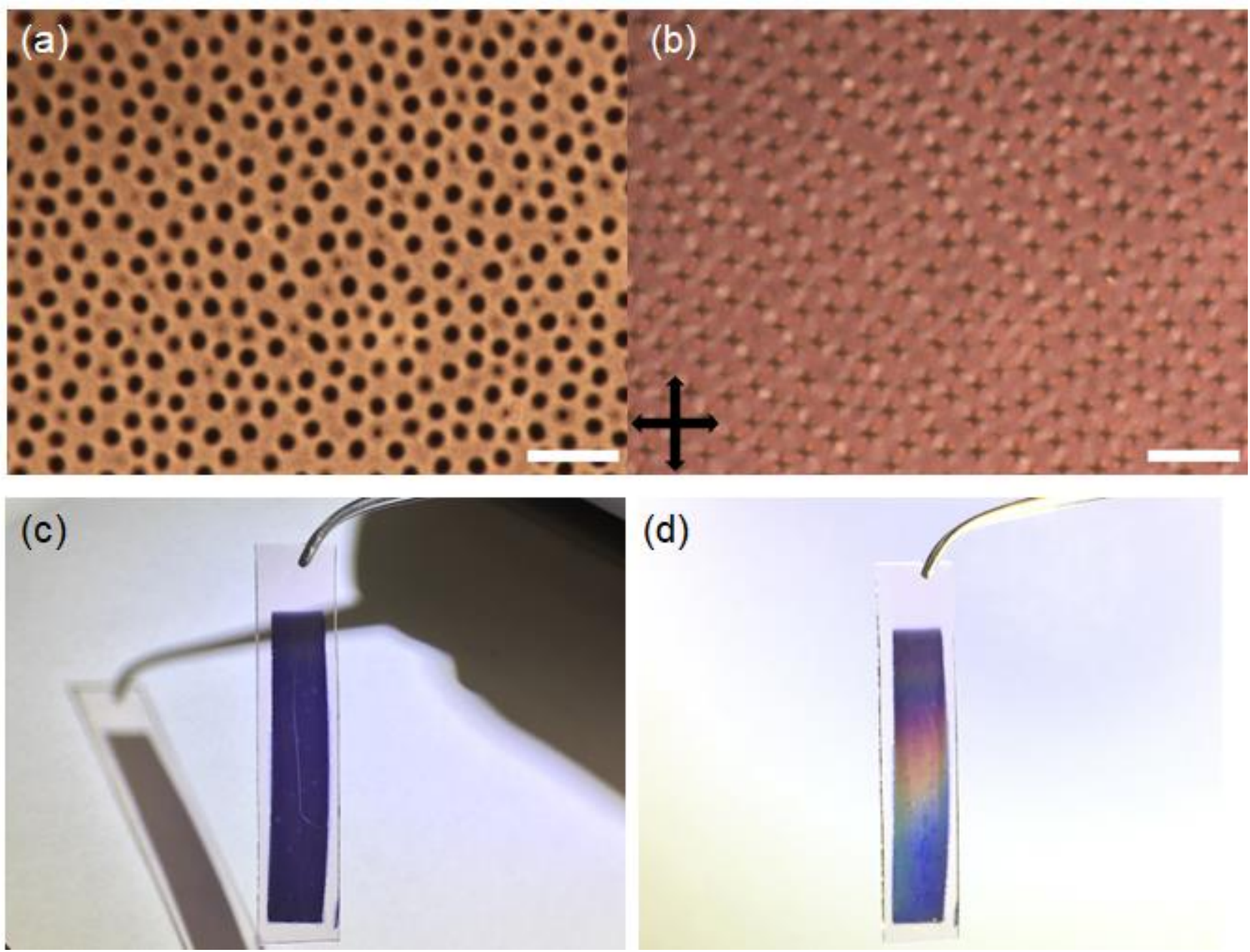

(d)

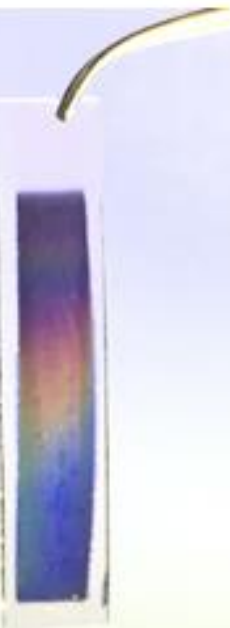

Figure 2. Optical microscopy image of the PEDOT_HPC_63 film (a) and a POM image of the PEDOT_HPC film showing a cross-shadow pattern (b). All scale bars are $10 \mu \mathrm{m}$. Normal appearance of the PEDOT_HPC film (c). The PEDOT_HPC film showing iridescent color under oblique incident white light $(\mathrm{d})$.

\subsection{Surface Morphology}

SEM and AFM observations were conducted to investigate the surface morphology. Figure 3a shows that the surface of the PEDOT_HPC_66 film has dots that are uniform in size and irregular in periodicity throughout a large area. Figure $3 \mathrm{~b}$ is a magnification of Figure $3 \mathrm{a}$. The results of the AFM observations are shown in Figure 3(c-h). Figure 3c includes an AFM image of the PEDOT_HPC_66 film of $10 \mu \mathrm{m} \times 10 \mu \mathrm{m}$ area, and Figure 3d is a 3D image of Figure 3c. Figure $3 \mathrm{e}$ is a cross-sectional image of the black line represented in Figure $3 \mathrm{c}$. This analysis revealed that the dot height is ca. $270 \mathrm{~nm}$, and the dot diameter is ca. $1.2 \mu \mathrm{m}$. Meanwhile, Figure $3(\mathrm{f}-\mathrm{h})$ shows an AFM image of one of the dots. Moreover, the film thickness was determined to be ca. $470 \mathrm{~nm}$ by AFM (Figure S2). Schematic illustrations of the dots are presented in Figure $3 i$. 
The aspect ratio of dot height and diameter was estimated to be 0.23 , indicating that the dots are like compressed hemispheres.
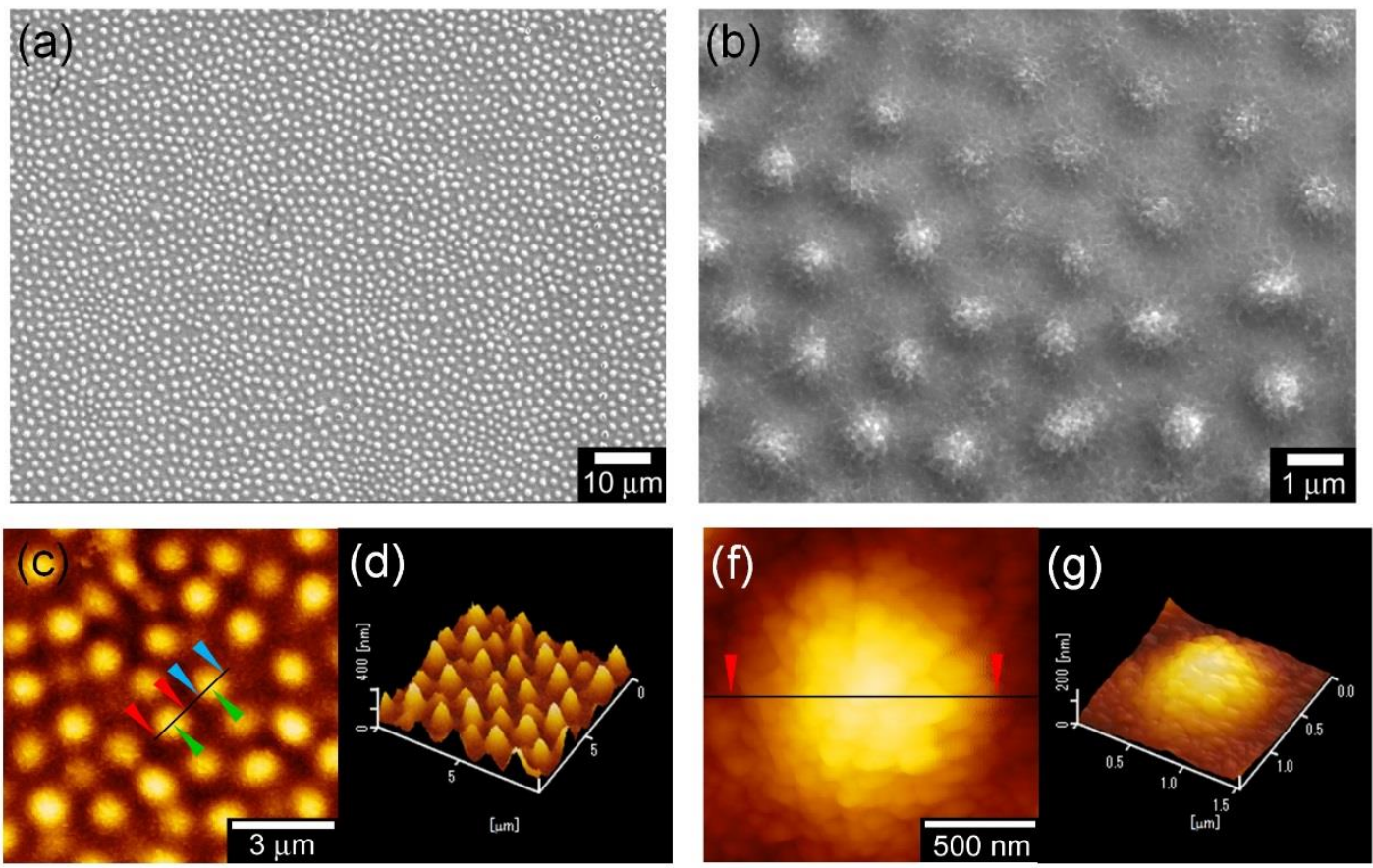

(e)

(h)
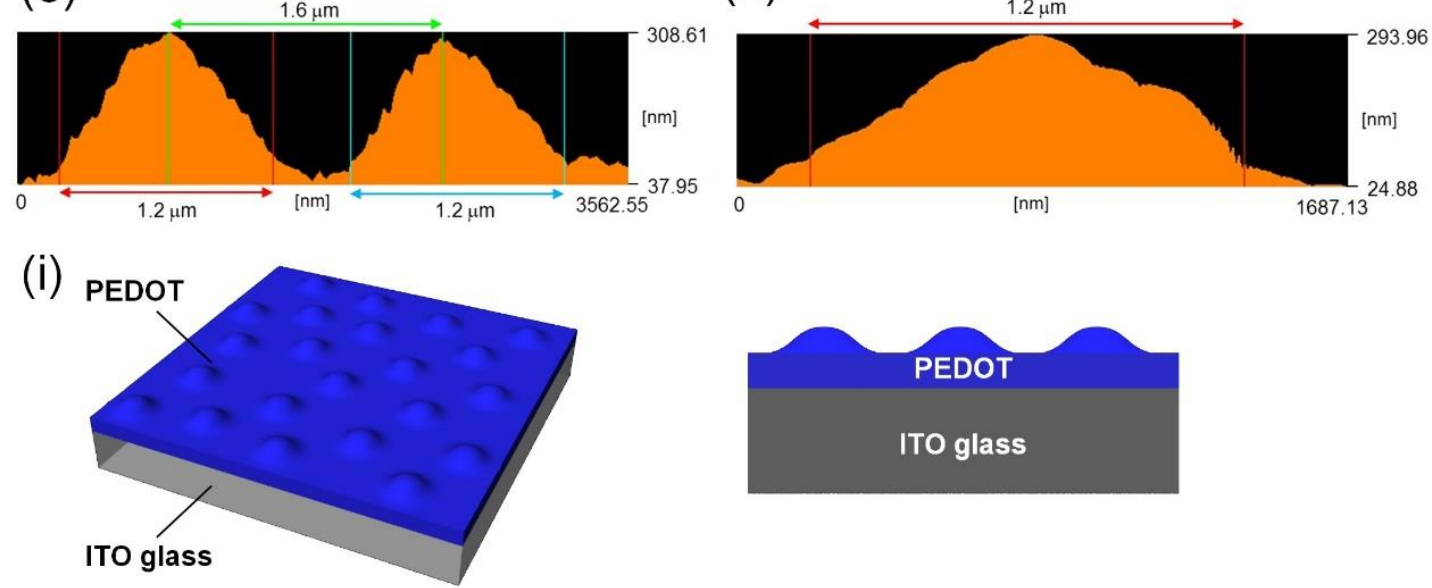

Figure 3. SEM images of the as-prepared PEDOT_HPC_66 film (a, b). AFM images of the asprepared PEDOT_HPC_66 film (c-h). 2D image of the PEDOT_HPC_66 film (c) and a 3D image of the PEDOT_HPC film (d). Figure $3 \mathrm{e}$ is a cross-sectional image of the black line in Figure $3 \mathrm{c}$. The red, blue, and green arrows of Figure $3 \mathrm{c}$ correspond to the vertical lines in the cross-sectional image of Figure 3e. An AFM image of one of the dots ( $\mathrm{f}-\mathrm{h})$. Figure $3 \mathrm{~h}$ is a crosssectional image of the black line and red arrows represented in Figure 3f. Schematic illustration of the PEDOT_HPC film (i).

POM observations of the electrolyte solution suggest that the HPC/DMF solution exhibits a polygonal focal conic morphology, which resembles those previously reported. ${ }^{47-50}$ Bouligand et 
al. reported a precise topological description of such polygonal texture along with a schematic representation (Figure 4) ${ }^{51}$ Rofouie et al. showed that the CLC forms periodic convex structures corresponding to the helical pitch due to changes in the surface energy. ${ }^{52}$ Furthermore, Agez et al. investigated the reflection color of a CLC by monitoring interface-induced deformations. ${ }^{53}$

(a)

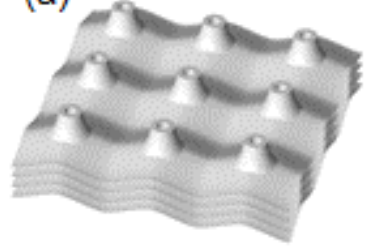

(b)

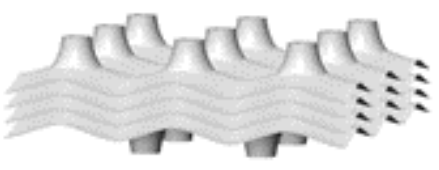

Figure 4. Schematic illustration of polygonal structure of cholesteric phase. Overhead view (a) and side view (b).

On the basis of these models, we propose the formation process for the dot structure generated during the electrochemical polymerization depicted in Figure 5. Figure 5 shows the schematic illustration of HPC liquid crystal aligning in ITO glass cell before electrochemical polymerization. Helical axis of cholesteric liquid crystal is parallel to the substrate. Half pitch of cholesteric liquid crystal corresponds to the distance between two bright stripes of POM image.

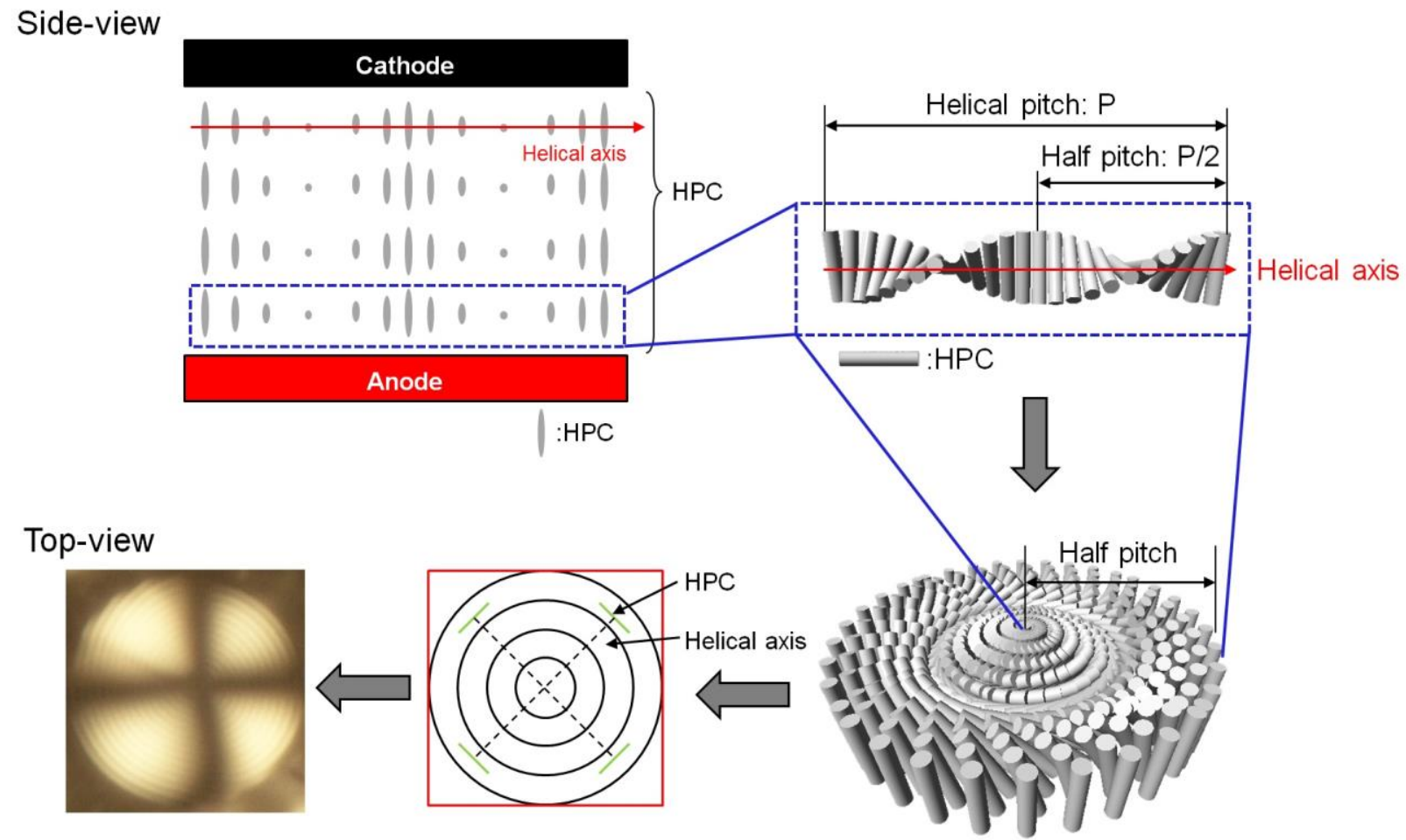

Figure 5. Schematic illustration of hydroxypropyl cellulose alignment in ITO glass cell. Topview image was taken under cross-polarizer. Distance between two bright stripes corresponds to half pitch of HPC cholesteric liquid crystal.

Careful observation of PEDOT thin film at initial state of the electrochemical polymerization reveals that fingerprint texture is transcribed to the PEDOT film slightly. The reason for slight 
texture is due to the thin film. Height analysis of fingerprint convex-concave analysis by AFM reveals that there was almost no unevenness (Figure S3a).

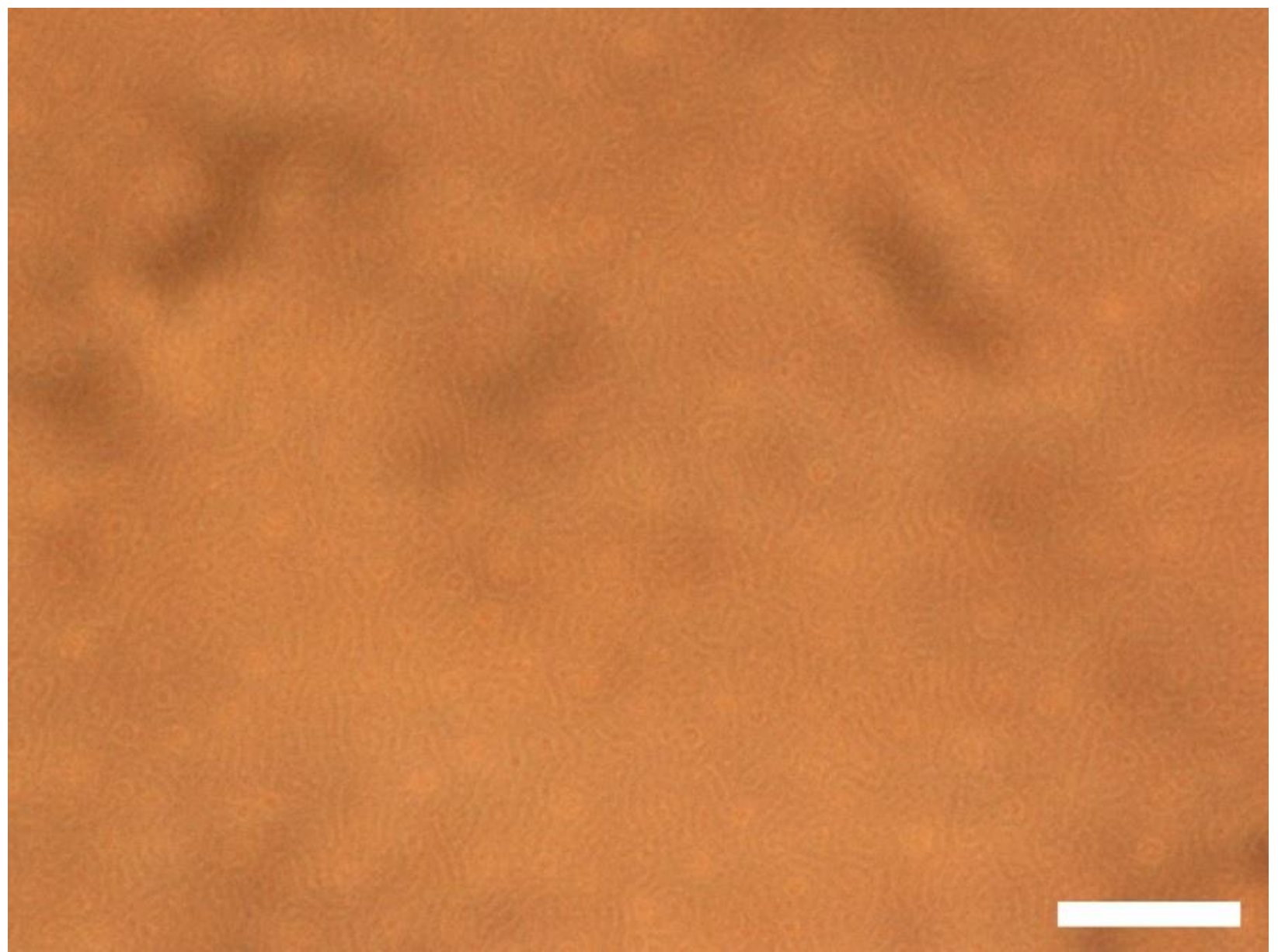

Figure 6. Optical microscope image of PEDOT_HPC_66 film when polymerization time is 10 minutes. Scale bar is $20 \mu \mathrm{m}$.

Figure 7 shows optical microscope (OM) images of PEDOT_HPC_66 film with difference of focus at the same place when polymerization time is 15 minutes. Figure $7 \mathrm{a}$ focuses on dot structures of initial states. Figure $7 \mathrm{~b}$ is the OM image at the same area of Figure $7 \mathrm{a}$. The focus of the optical microscope shifted in a direction of approaching the ITO substrate. When electrochemical polymerization proceeds and polymerization time is 15 minutes, nuclei of dot structures are emerged on the PEDOT film. The number of dots is less than that of final state PEDOT film and the size of dots is smaller than that of final state PEDOT film. As a result, fingerprint texture was observed behind the dot structures. These results indicate that the transcription of homeotropically aligned cholesteric liquid crystal is occurred at first, and then nuclei of dot structures grow. 


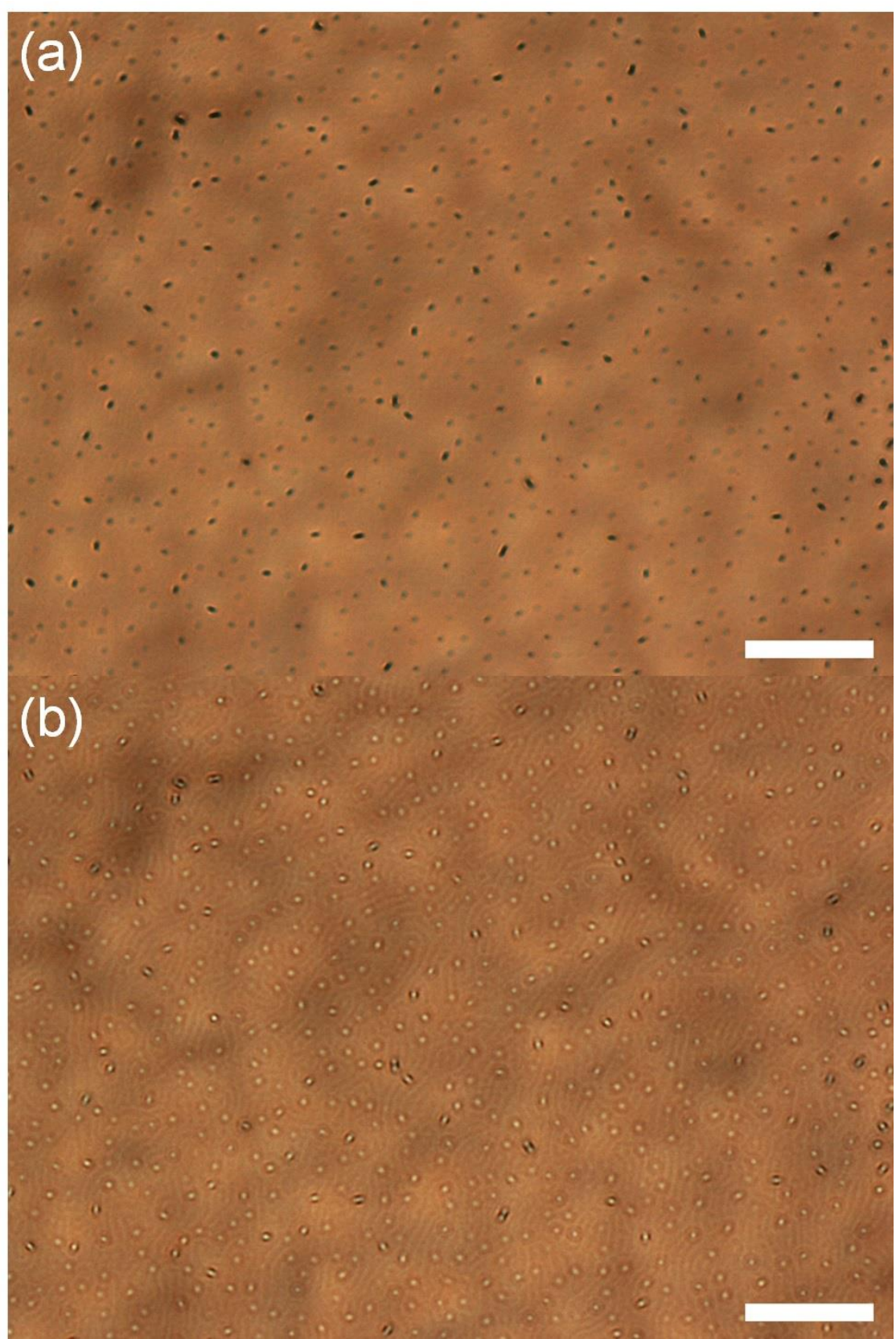

Figure 7. Optical microscope images of a PEDOT_HPC_66 film when polymerization time is 15 min. Pint of optical microscope focuses on dot structures (a) and fingerprint textures (b) at the same area. All scale bars are $20 \mu \mathrm{m}$.

From these results, possible formation mechanism of dot structures during electrochemical polymerization is proposed. Before the polymerization, the HPC liquid crystal forms a helical structure derived from the cholesteric phase (Figure 8a). In the early stages of the electrochemical polymerization, PEDOT is deposited onto the entire area of the anode (Figure $8 \mathrm{~b}$ ), causing changes in the surface energy due to PEDOT thin layer formation. As shown in Figure 6, the PEDOT film at initial state shows fingerprint texture derived from transcription of homeotropic alignment of HPC LC (Figure 8b). AFM also reveals that the PEDOT film shows 
fingerprint texture (Figure S3). In the step c, the surface of the HPC forms a convex texture near the surface region of the ITO glass due to the deformation of polygonal structure. Furthermore, the convex PEDOT structures grow along the HPC structures as shown in Figure 8c. Optical microscope observation of PEDOT film suggests that the size of dots at early state is small and number of dots is less than that of final state (Figure 7). As the electrochemical polymerization proceeds, the size of dots grows, and the number of dots increases. Finally, periodic PEDOT structures are formed (Figure 8d). The appearance of distorted surface of the CLC near the surface region generates dot structures and are greater than half helical pitch of the electrolyte solution $^{50}$. The relationship between half helical pitch of the electrolyte solution and size of dot structures are discussed in later section in detail.

(a)

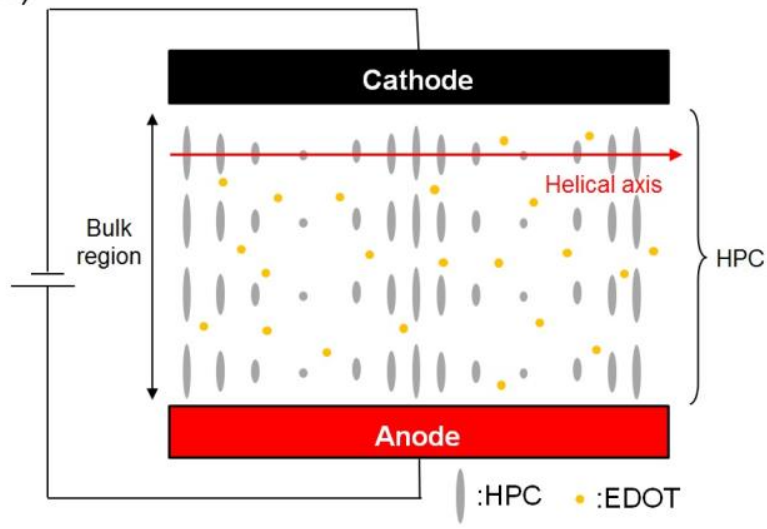

(b)

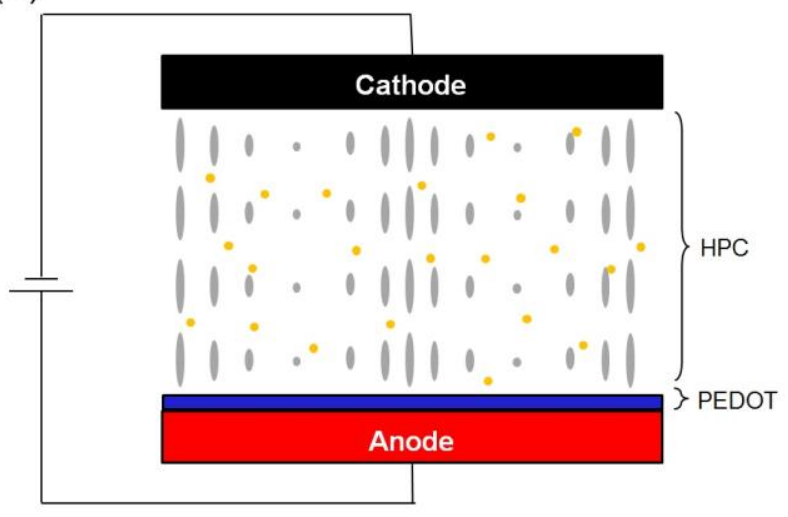

(c)

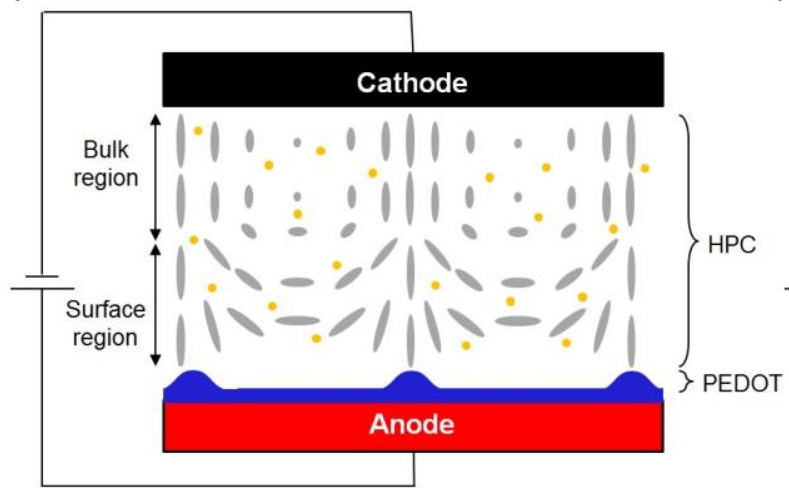

(d)

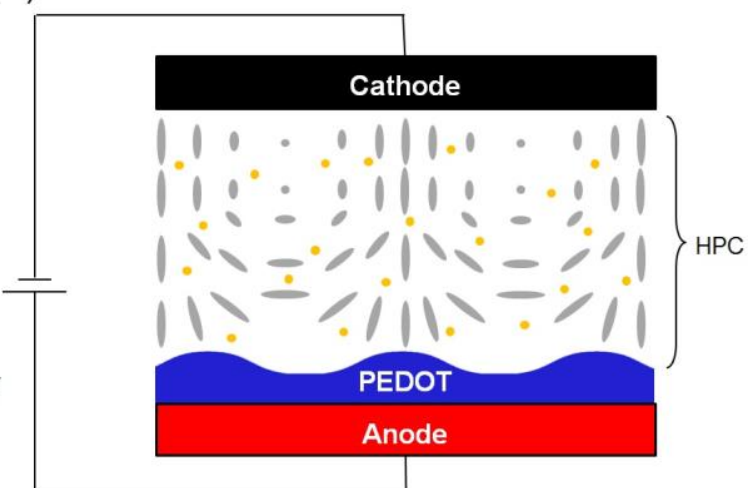

Figure 8. Proposed formation mechanism of the convex PEDOT structure during electrochemical polymerization in the HPC cholesteric liquid crystal. Gray ellipses show HPC molecular. Yellow circles show EDOT monomer. Before the polymerization (a), initial state of the polymerization (b), intermediate state of the polymerization (c), and final state of the polymerization (d).

\subsection{Electrochromic Property}

In situ UV-vis absorption measurements were performed via cyclic voltammetry to investigate the electrochromic properties of the PEDOT_HPC film. An acetonitrile solution containing 0.1 
M TBAP was used as the electrolyte solution. Cyclic voltammogram of the PEDOT_HPC film are shown in Figure S4. The UV-vis absorption spectra recorded during the oxidation process are shown in Figure 9a. The absorption band at $551 \mathrm{~nm}$ attributed to a $\pi-\pi^{*}$ transition at the reduced state of the film was found to decrease with applied voltage. In contrast, a new absorption band at $713 \mathrm{~nm}$ ascribable to a polaron (radical and cation) appears and increases with applied voltage. The color of the PEDOT_HPC film changes from purple to blue with applied voltage (Figure 9b). The optical transmittance changes at 551 and $713 \mathrm{~nm}$ was examined with an applied voltage between $-0.8 \mathrm{~V}$ (dedoping) and $+0.9 \mathrm{~V}$ (doping) with an interval time of $20 \mathrm{~s}$. The corresponding transmittance and current plots as a function of time at 551 and $713 \mathrm{~nm}$ are shown in Figure $9(\mathrm{c}-\mathrm{f})$. The optical contrast $(\Delta \mathrm{T})$ was determined to be $18 \%$ and $22 \%$ at 551 and $713 \mathrm{~nm}$, respectively. The time required for $90 \%$ change of $\Delta \mathrm{T}$ at $551 \mathrm{~nm}$ between the oxidized and reduced state is $2.3 \mathrm{~s}$ and $5.6 \mathrm{~s}$, respectively. The electrochromic properties including color efficiency $(\eta)$ are summarized in Table 2. 
(a)

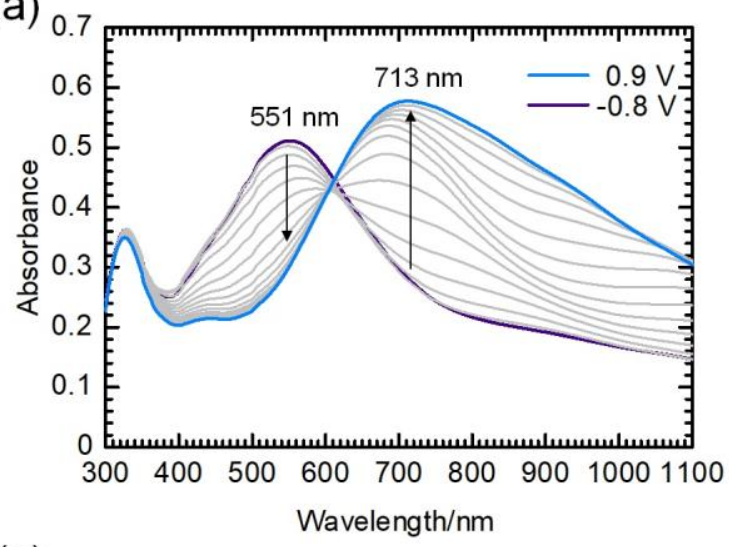

(c)

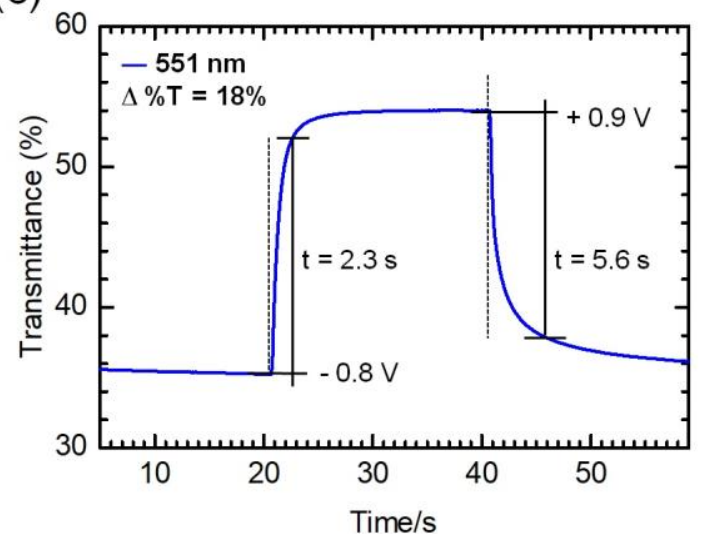

(e)

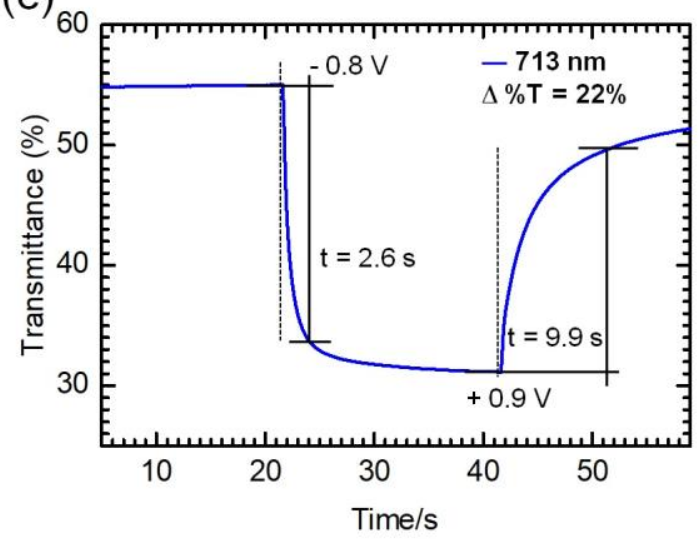

(b)

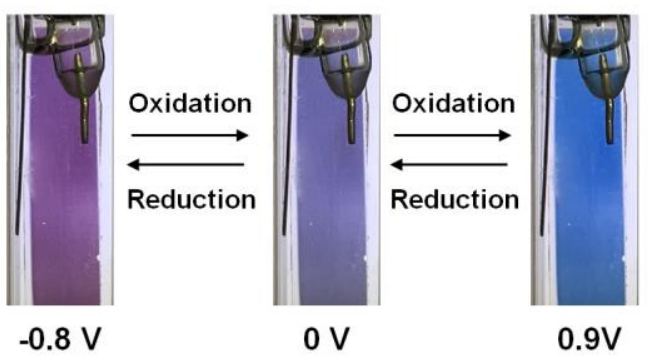

(d)

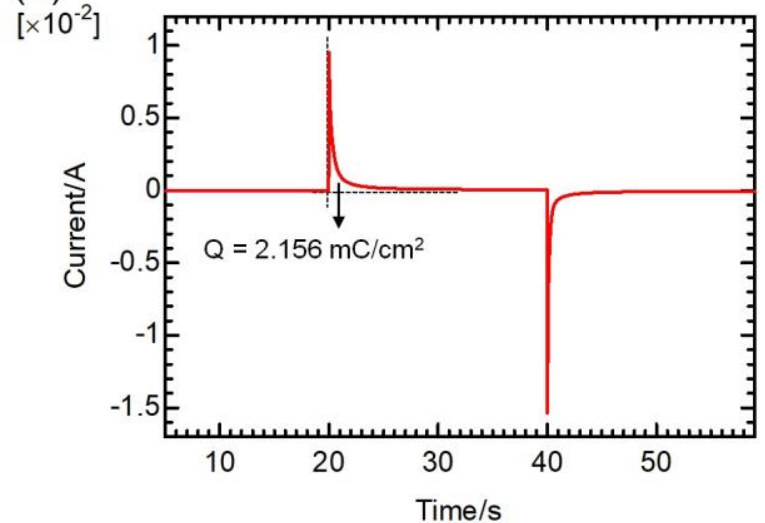

(f)

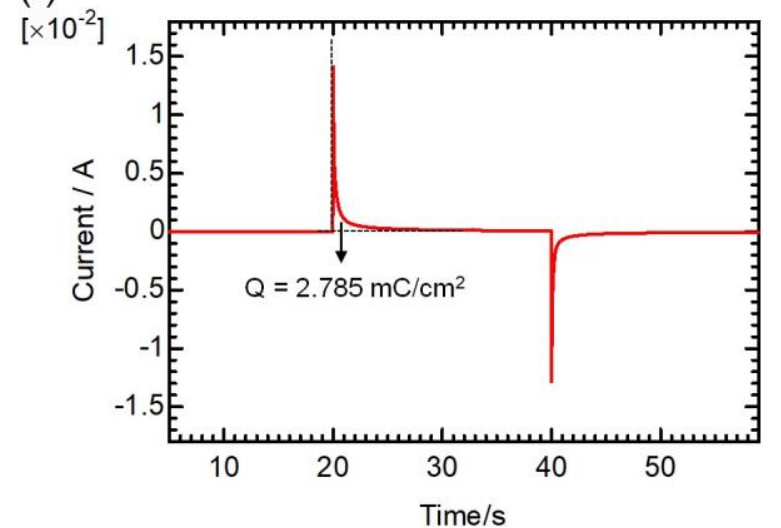

Figure 9. In situ UV-vis absorption spectra of the PEDOT_HPC film between $-0.8 \mathrm{~V}$ (reduced state) and $+0.9 \mathrm{~V}$ (oxidized state) (a). The color of the PEDOT_HPC film changes from purple to blue (b). Change in transmittance after the first cycle of the PEDOT_HPC film at $551 \mathrm{~nm}$ (c) and $713 \mathrm{~nm}(\mathrm{e})$. Charge/discharge quantity of electric charge of the PEDOT_HPC film at $551 \mathrm{~nm}(\mathrm{~d})$ and $713 \mathrm{~nm}(\mathrm{f})$ with an applied voltage between -0.8 and $+0.9 \mathrm{~V}$. 
Table 2. Electrochromic properties of the PEDOT_HPC film with an applied voltage between $-0.8 \mathrm{~V}$ and $+0.9 \mathrm{~V}$.

\begin{tabular}{|c|c|c|c|c|c|c|c|}
\hline \multirow[t]{2}{*}{ Polymer } & \multirow[t]{2}{*}{$\lambda_{\max }(\mathrm{nm})$} & \multirow[t]{2}{*}{$\Delta \% \mathrm{~T}$} & \multicolumn{2}{|c|}{ Response time ${ }^{\mathrm{a}}$} & \multirow[t]{2}{*}{$\Delta \mathrm{OD}^{\mathrm{b}}$} & \multirow{2}{*}{$\begin{array}{l}\text { Charge/discharge } \\
\text { amount } \\
\mathrm{Q}^{\mathrm{c}}\left(\mathrm{mC} / \mathrm{cm}^{2}\right)\end{array}$} & \multirow{2}{*}{$\begin{array}{l}\text { Color } \\
\text { efficiency } \\
\eta^{\mathrm{d}} \\
\left(\mathrm{cm}^{2} / \mathrm{C}\right)\end{array}$} \\
\hline & & & $\mathrm{T}_{\text {oxidized }}$ & $\mathrm{T}_{\text {reduced }}$ & & & \\
\hline \multirow[t]{2}{*}{ PEDOT_HPC } & 551 & 18 & 2.3 & 5.6 & 0.18 & 2.156 & 83.9 \\
\hline & 713 & 22 & 2.6 & 9.9 & 0.23 & 2.785 & 84.3 \\
\hline
\end{tabular}

a Time for $90 \%$ of the full-transmittance change. $\mathrm{b}$ Optical density $(\Delta \mathrm{OD})=\log \left[\mathrm{T}_{\text {reduced }} / \mathrm{T}_{\text {oxidized }}\right]$, where $\mathrm{T}_{\text {reduced }}$ and $\mathrm{T}_{\text {oxidized }}$ are the maximum transmittance in the reduced and oxidized states, respectively. c Q is charge and discharge amount, determined from chronoamperometry. $\mathrm{d}$ Coloration efficiency $(\mathrm{CE})=\Delta \mathrm{OD} / \mathrm{Q}$.

\subsection{HPC Concentration Dependency of Dot Size}

To evaluate the dependence of the dot size on the HPC concentration, electrolyte solutions were prepared at various concentrations ranging from $54.0 \mathrm{wt} \%$ to $66.0 \mathrm{wt} \%$. Optical microscope observation of the obtained PEDOT_HPC films reveals that the dot size decreases with increasing of HPC concentration (Figure 10(a-d)). The corresponding dot areas were calculated by using image analysis software (ImageJ) (Figure 10(e-h)). ${ }^{54}$ Half helical pitches of the electrolyte solutions are estimated from POM observations (Figure S5). The dot area, diameter and half helical pitch of the electrolyte solutions are summarized in Table 3. These results indicate that the dot area tends to decrease with increasing of HPC concentration. Generally, the helical pitch of a lyotropic CLC decreases with increasing of concentration. Accordingly, these results suggest that the half helical pitch of the HPC liquid crystal affects the formation of the dots as mentioned above and periodicity.

Table 3. Helical pitch of electrolyte solutions and calculated diameter of dot structures.

\begin{tabular}{llll}
\hline Entry & Area $\left(\mu \mathrm{m}^{2}\right)$ & Diameter $^{\mathrm{a}}(\mu \mathrm{m})$ & Half helical pitch ${ }^{\mathrm{b}}(\mu \mathrm{m})$ \\
\hline PEDOT_HPC_54 & 3.23 & 2.03 & 0.85 \\
PEDOT_HPC_58 & 2.47 & 1.78 & 0.79 \\
PEDOT_HPC_62 & 1.89 & 1.55 & 0.63 \\
PEDOT_HPC_66 & 0.95 & 1.10 & 0.59 \\
\hline
\end{tabular}

a Diameters are calculated from dot area.

b Half helical pitches are calculated from POM images of the HPC electrolyte solution by ImageJ. 


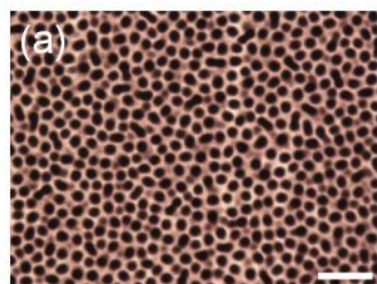

(e)

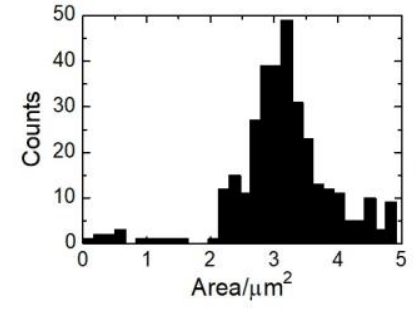

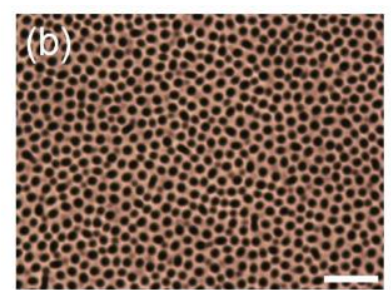

(f)

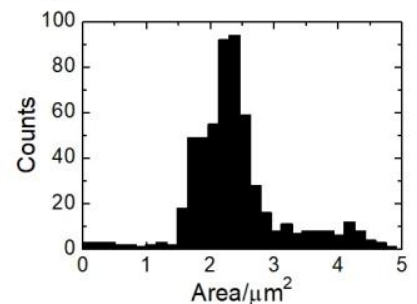

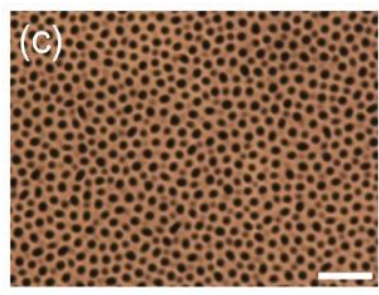

(g)

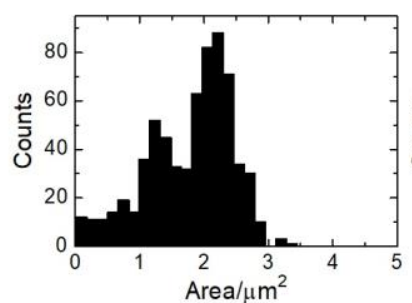

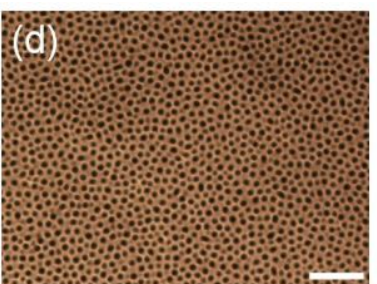

(h)

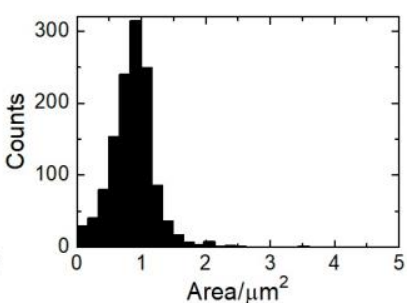

Figure 10. Optical images of PEDOT_HPC films at concentrations of $54.0 \mathrm{wt} \%, 58.0 \mathrm{wt} \%$, $62.0 \mathrm{wt} \%$, and $66.0 \mathrm{wt} \%$, respectively (a-d). All scale bars are $10 \mu \mathrm{m}$. Histograms of dot area calculated by ImageJ at concentrations of $54.0 \mathrm{wt} \%, 58.0 \mathrm{wt} \%, 62.0 \mathrm{wt} \%$ and $66.0 \mathrm{wt} \%$, respectively (e-h). The mean values of dot area at each concentration are 3.23, 2.47, 1.89, and 0.95 , respectively. Standard deviations at each concentration are $0.78,0.74,0.64$, and 0.33 , respectively.

\subsection{Diffraction Grating}

The PEDOT_HPC films having dots on the surface of the ITO glass shows diffraction grating properties in both transmission and reflection modes due to the hemisphere dots. When light is incident on the surface of the diffraction grating, the maximum diffraction angle can be expressed as follows ${ }^{55}$ :

$$
d(\sin \alpha+\sin \beta)=m \lambda
$$

where $\mathrm{d}$ is the distance between gratings, $\alpha$ is the incident light angle, $\beta$ is the diffracted light angle, $\mathrm{m}$ is the diffraction order, and $\lambda$ is the wavelength. Left side of an equation means the optical path difference of incident light and diffracted light. When the optical path difference equals the wavelength, light will be intensified by interference.

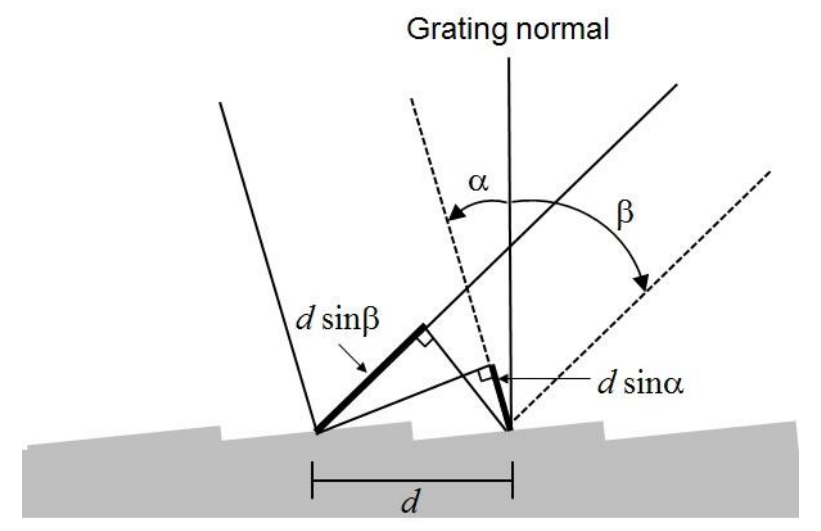

Figure 11. Schematic illustration of diffraction grating. $\alpha$ and $\beta$ are incident light angle and diffracted light angle, respectively. $d$ is grating space. 
Upon incidence of green laser light (wavelength $=532 \mathrm{~nm}$ ) on the PEDOT_HPC film at the reduced state, a diffraction ring $(\mathrm{m}=1)$ can be observed on the screen (Figure 12).

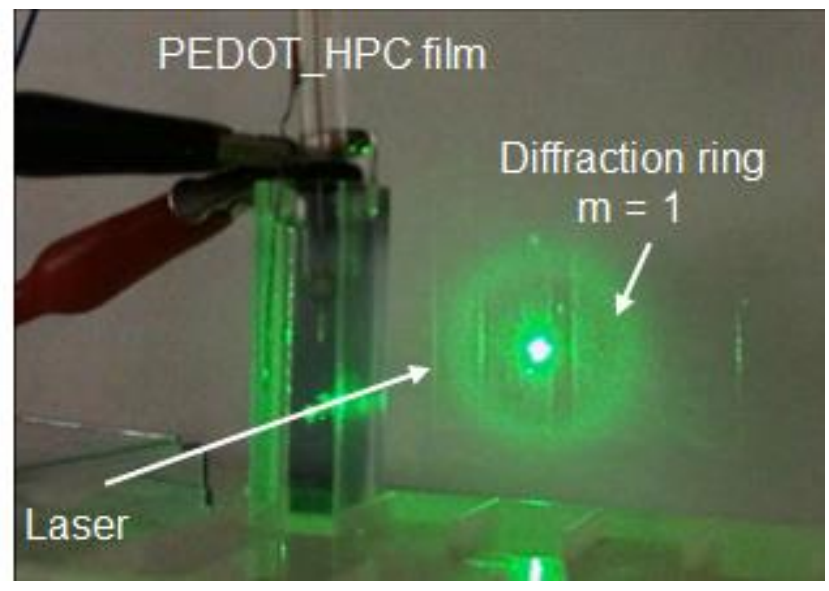

Figure 12. Diffraction ring upon incidence of the green laser to the PEDOT_HPC film at a reduced state.

\subsubsection{Transmission-Type Grating}

Angle scan measurements from $5^{\circ}$ to $35^{\circ}$ of the transmittances on the as-prepared PEDOT_HPC_66 film deposited on the ITO glass are shown in Figure 13a. The maximum diffraction angles were determined to be $16.5^{\circ}, 21.0^{\circ}$, and $29.0^{\circ}$ for 436,546 , and $700 \mathrm{~nm}$, respectively. The normalized reflection spectra of the transmission diffraction are displayed in Figure 13b. As can be seen, the maximum reflection wavelength red shifts when the detection angle changes from $10^{\circ}$ to $30^{\circ}$. This result is a typical phenomenon of gratings. Commission internationale de l'éclairage (CIE) color space diagram for the as-prepared PEDOT_HPC film is shown in Figure 13c, which reveals that the transmission color of the polymer film at $10^{\circ}$ is in the blue region. The color plots gradually move from blue to red via green as the detection angle increases to $30^{\circ}$. Changes in the transmittance of diffracted light at the reduced and oxidized states of the PEDOT_HPC film with applied voltage were also examined. To this aim, the PEDOT_HPC film was oxidized and reduced by the potentiostat between -0.8 and $+0.9 \mathrm{~V}$, respectively. The corresponding angle scan measurements are shown in Figure 13d. It was found that the maximum diffraction angles remain unaltered at 436, 546, and $700 \mathrm{~nm}$. However, the intensity of the reflectance at $436 \mathrm{~nm}$ increases with oxidation, whereas those at 546 and $700 \mathrm{~nm}$ decrease with oxidation. This can be attributed to the difference in optical absorption between oxidized state and reduced state. The CIE color space diagrams of the diffracted light transmitted by the PEDOT_HPC_66 film in the reduced state and the oxidized state are shown in Figure 13 $(\mathrm{e}, \mathrm{f})$. The transmission light diffraction color of the oxidized state shifts slightly toward the blue region compared with the reduced state. 
(a)

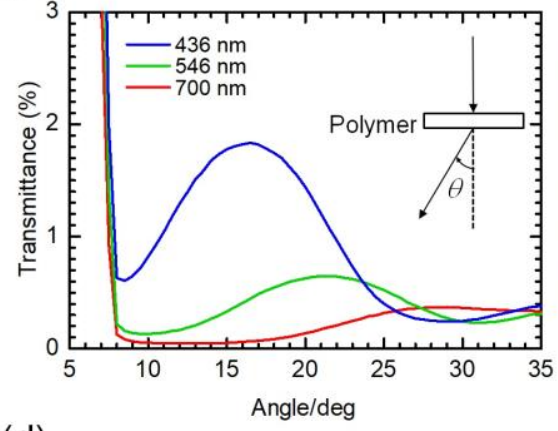

(d)

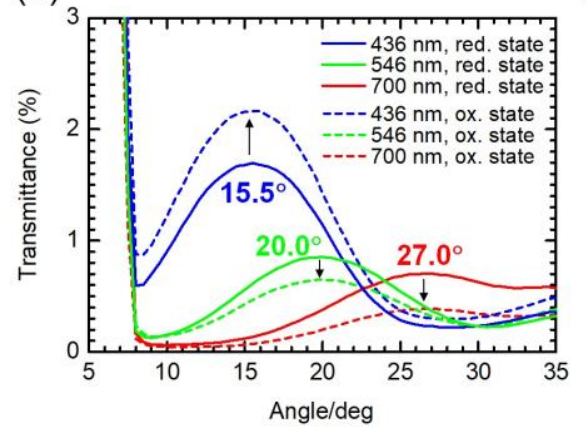

(b)

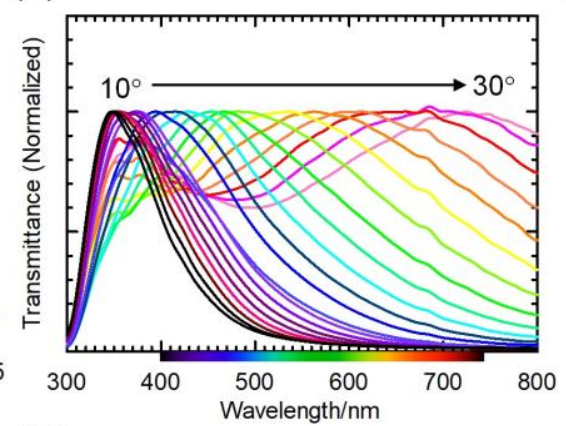

(e)

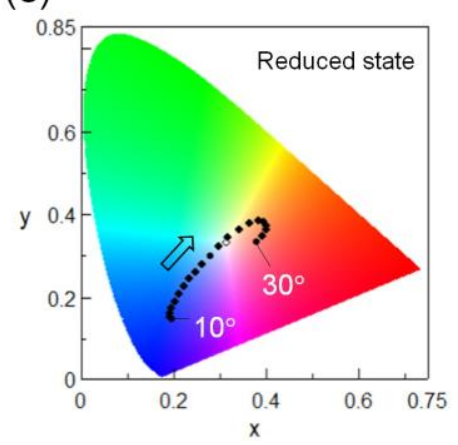

(c)

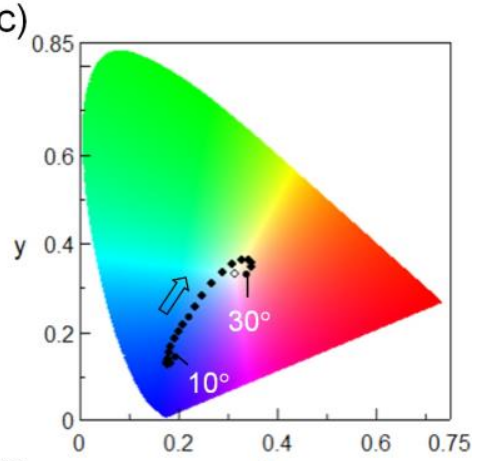

(f)

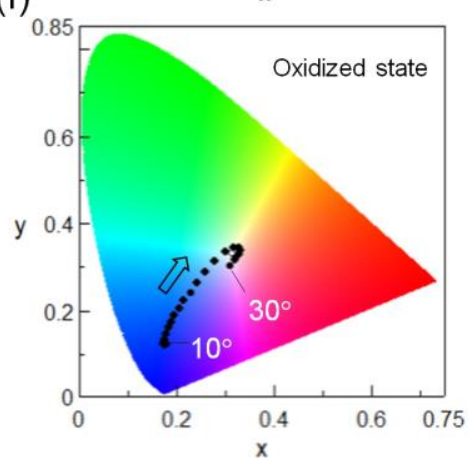

Figure 13. Angle scan measurements of the transmittance on the PEDOT_HPC_66 film at an incident light angle of $0^{\circ}$ (a). Blue, green, and red lines correspond to $43 \overline{6}, 54 \overline{6}$, and $700 \mathrm{~nm}$ wavelength, respectively. Diffracted transmission spectra of the PEDOT_HPC_66 film from $10^{\circ}$ to $30^{\circ}$ of detection angle (b). CIE color space diagram of the as-prepared PEDOT_HPC_66 film from $10^{\circ}$ to $26^{\circ}$ of detection angle (c). Angle scan measurements on the PEDOT_HPC_66 film at the reduced state (solid line) and oxidized state (dashed line) (d). Blue, green, and red lines correspond to 436, 546, and $700 \mathrm{~nm}$, respectively. CIE color space diagram of the PEDOT_HPC_66 film at the reduced state (e) and oxidized state (f).

\subsubsection{Reflection-Type Grating}

The PEDOT_HPC film also shows reflection-type diffraction grating properties. Angle scan measurements of the reflectance on the PEDOT_HPC_66 film were performed at incident light wavelengths of 436, 546, and $700 \mathrm{~nm}$, and the results are shown in Figure 14a. When the incident angle is $30^{\circ}$, diffraction light is observed in two regions due to the -1 and +1 diffraction order. For incident light at 436, 546, and $700 \mathrm{~nm}$, the maximum reflectance angles are $17.5^{\circ}$, $13.5^{\circ}$, and $9.0^{\circ}$ in the +1 order region (Figure 10a) and $44.5^{\circ}, 47.5^{\circ}$, and $55.0^{\circ}$ in the -1 order region, respectively (Figure 14b). The corresponding reflection spectra are displayed in Figures $10(\mathrm{c}, \mathrm{d})$. As can be seen, the maximum reflection wavelength gradually shifts toward the blue region as the reflection angle changes from $0^{\circ}$ to $20^{\circ}$. In contrast, the maximum reflection wavelength gradually red shifts as the detection angle increases from $40^{\circ}$ to $70^{\circ}$. These results are consistent with those of the angle scan measurements. The CIE color space diagrams calculated from the reflection spectra are shown in Figure 14(e, f). The diffracted light changes from red to blue when the detection angle varies from $0^{\circ}$ to $20^{\circ}$. Conversely, the diffracted light changes from blue to red with the detection angle changing from $40^{\circ}$ to $70^{\circ}$. The angle scan 
measurements, reflection spectra, and CIE color space diagram at incident angles of $45^{\circ}$ and $60^{\circ}$ are available in Figure S6-S10.

(a)

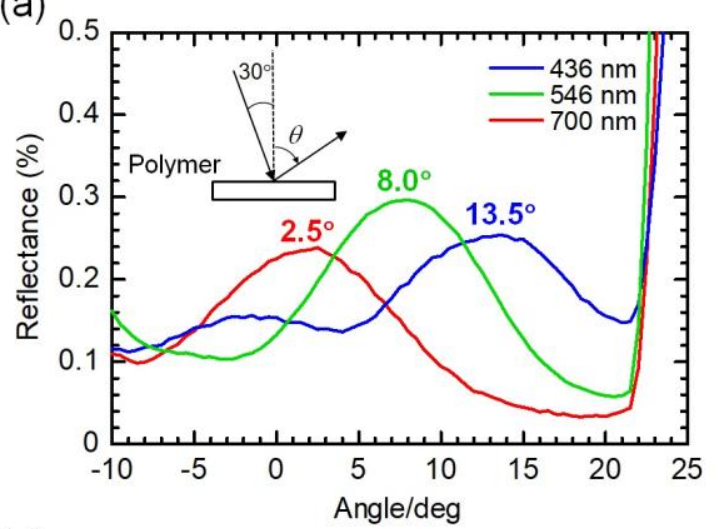

(c) 0

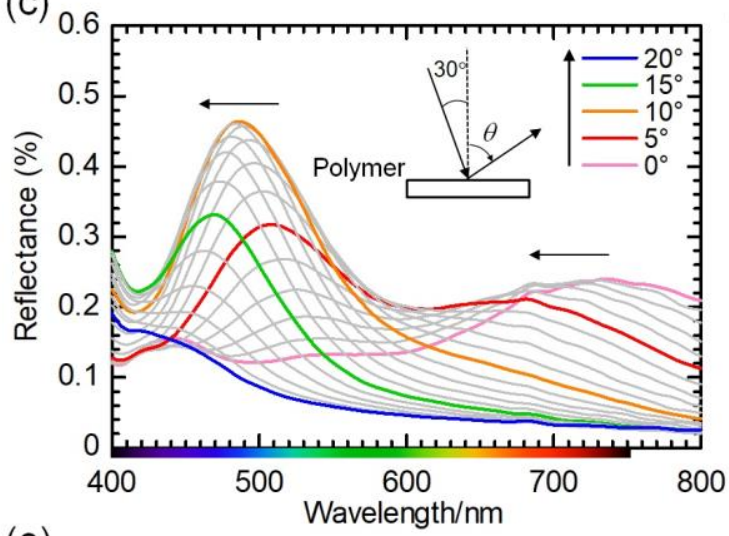

(e)

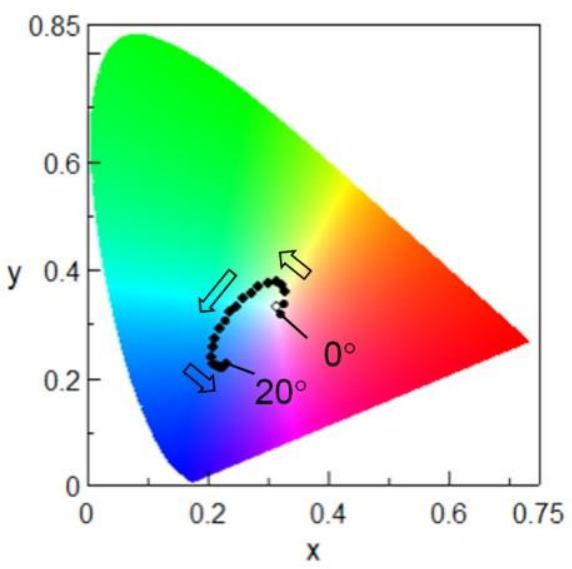

(b)

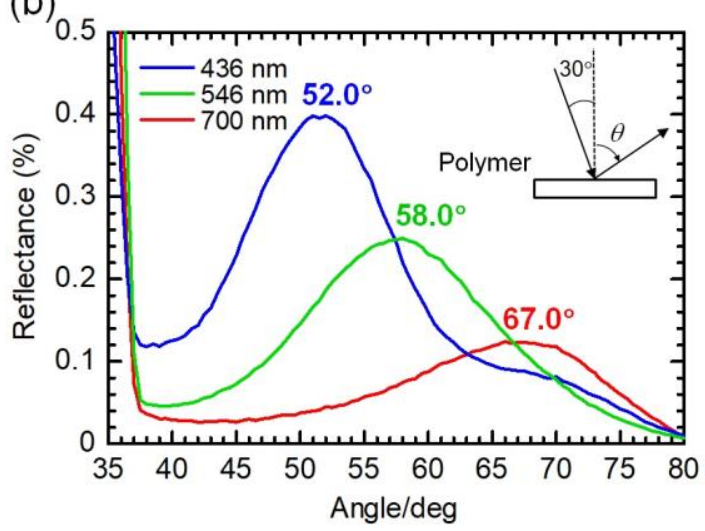

(d)

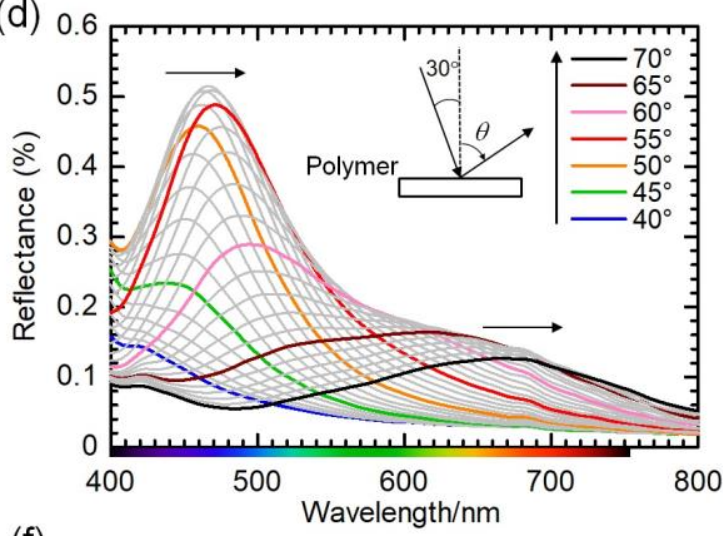

(f)

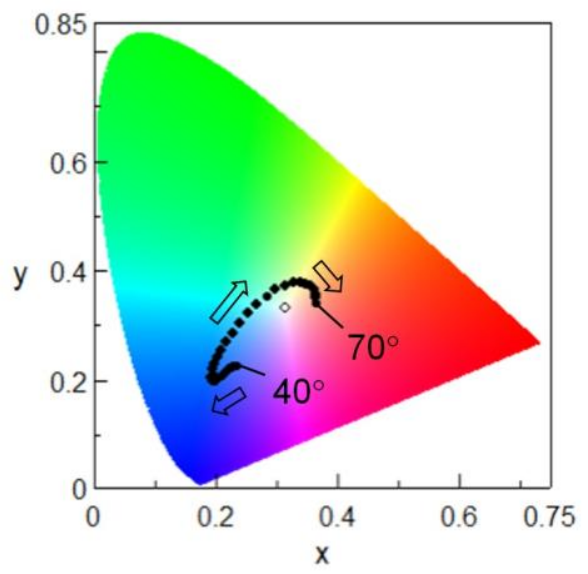

Figure 14. Angle scan measurements of the reflectance on the PEDOT_HPC_66 film at an incident angle of $30^{\circ}(\mathrm{a}, \mathrm{b})$. Blue, green, and red lines correspond to $4 \overline{3} \overline{6}, 54 \overline{6}$, and $700 \mathrm{~nm}$ wavelength, respectively. Reflection spectra of the PEDOT_HPC_66 film at an incident angle of $30^{\circ}$ with detection angle from $0^{\circ}$ to $20^{\circ}$ (c) and from $40^{\circ}$ to $70^{\circ}$ (d). CIE color space diagram of the PEDOT_HPC film at detection angle from $0^{\circ}$ to $20^{\circ}$ (e) and from $40^{\circ}$ to $70^{\circ}$ (f).

\subsubsection{Diffracted Light Angle Dependency of Dot Diameter}


We also evaluated the relationship between dot diameters and diffracted light angle. To this aim, the dot diameters were calculated by ImageJ software from the optical microscope images. The mean value of each dot diameter is determined to be $2.03,1.78,1.56$, and $1.10 \mu \mathrm{m}$ at a concentration of $54.0 \mathrm{wt} \%, 58.0 \mathrm{wt} \%, 62.0 \mathrm{wt} \%$, and $66.0 \mathrm{wt} \%$, respectively. All angle scan measurement results of each HPC concentration are available in Figure S11. Figure 15 shows a plot of the diffracted light angle as a function of dot diameter at an incident light angle of $30^{\circ}$, in which the widening of the diffracted light angle with decreasing the dot diameter can be observed in both -1 and +1 diffraction order regions. This result indicates that the PEDOT_HPC film having small dot diameter shows small "d" value in Equation 1 because the inter-dot distance decreases with the size of the dots (Figure 15(b, c)). As mentioned in the former section, the dot diameter depends on the HPC concentration. Therefore, the diffracted light angle can be tuned easily by changing the HPC concentration.

(a)

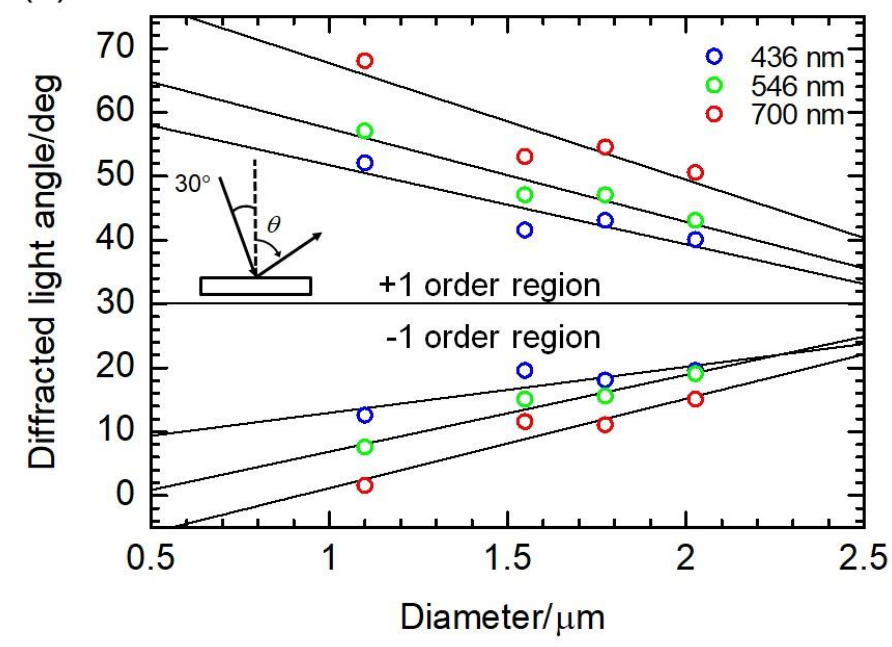

(b) Large diameter (low HPC concentration)

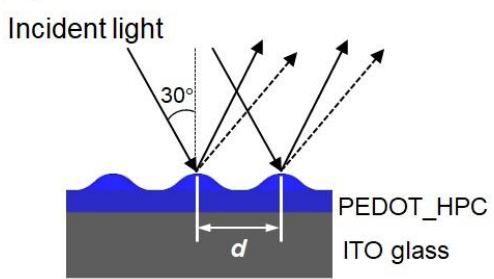

(C) Small diameter (high HPC concentration)

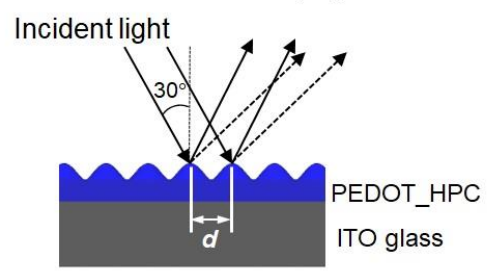

Figure 15. Plots of diffracted light angle as a function of dot diameter (a). The black lines are approximations by linear polynomial functions at each wavelength. Schematic illustrations of the light diffraction at large dot diameter (b) and small dot diameter (c).

\subsection{Metal Coating}

$\mathrm{Au}$ coating on the surface of the PEDOT_HPC film was demonstrated to enhance the diffracted light intensity. Although PEDOT-HPC film has diffraction grating property, reflection intensity is very low due to the polymer surface that is hard to reflect light. Therefore, Au was coated on the surface of the PEDOT film to enhance the reflection intensity. The thickness of the $\mathrm{Au}$ film is plotted as a function of coating time in Figure S12. From the plot, the expected deposition rate of $\mathrm{Au}$ was estimated to be $27 \mathrm{~nm} / \mathrm{min}$. Figure 16a shows a reflection optical microscopy image for the Au-coated PEDOT_HPC_66 film obtained after a coating time of five minutes. The inset photograph shows a strong iridescent reflection upon white light irradiation. Surface observation by AFM reveals no morphology change before and after Au deposition (Figure 16(b,c)), which indicates that the Au layer is uniformly deposited on the surface of the film. The CIE color spectra of PEDOT_HPC_66 film with no Au coating and with Au coatings of 13 and $113 \mathrm{~nm}$ are shown in Figure S13. 

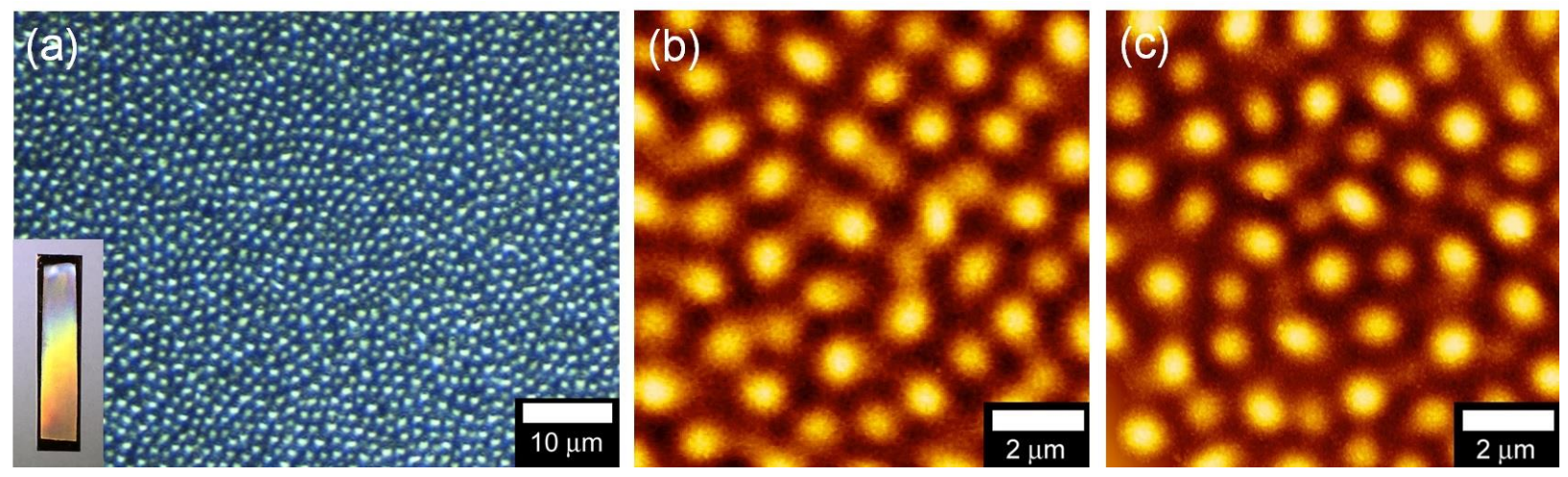

Figure 16. Reflection microscopy images of the PEDOT_HPC_66 film coated with Au for 5 min (inset: the Au-coated PEDOT_HPC_66 film showing iridescence upon irradiation of white light) (a). AFM image of the PEDOT_HPC_66 film before Au coating (b) and after Au coating (c).

Angle scan measurements of the reflectance on the PEDOT_HPC_66 film with various thicknesses of Au layer were performed at 436, 546, and $700 \mathrm{~nm}$ wavelength at an incident light angle of $30^{\circ}$ (Figure 17a). At all wavelengths, the reflection intensity was found to increase more than tenfold compared with films without the metal coating. Interestingly, a new reflection peak appears at approximately $-3^{\circ}$ (Figure $17(\mathrm{a}-\mathrm{c})$ ), which can be attributed to the second-order diffracted light $(\mathrm{m}=2)$. The second-order diffracted light is also observed at incident light angles of $45^{\circ}$ and $60^{\circ}$. These results are summarized in Figures S14-S15. Figure 17(d) shows the reflection intensity as a function of $\mathrm{Au}$ thickness. As can be seen, the reflection intensity increases with the Au thickness up to ca. $50 \mathrm{~nm}$. However, further Au thickness increase does not affect the reflection intensity. Therefore, the thickness of Au layer is enough within $50 \mathrm{~nm}$ for the improvement of reflectance intensity. 
(a)
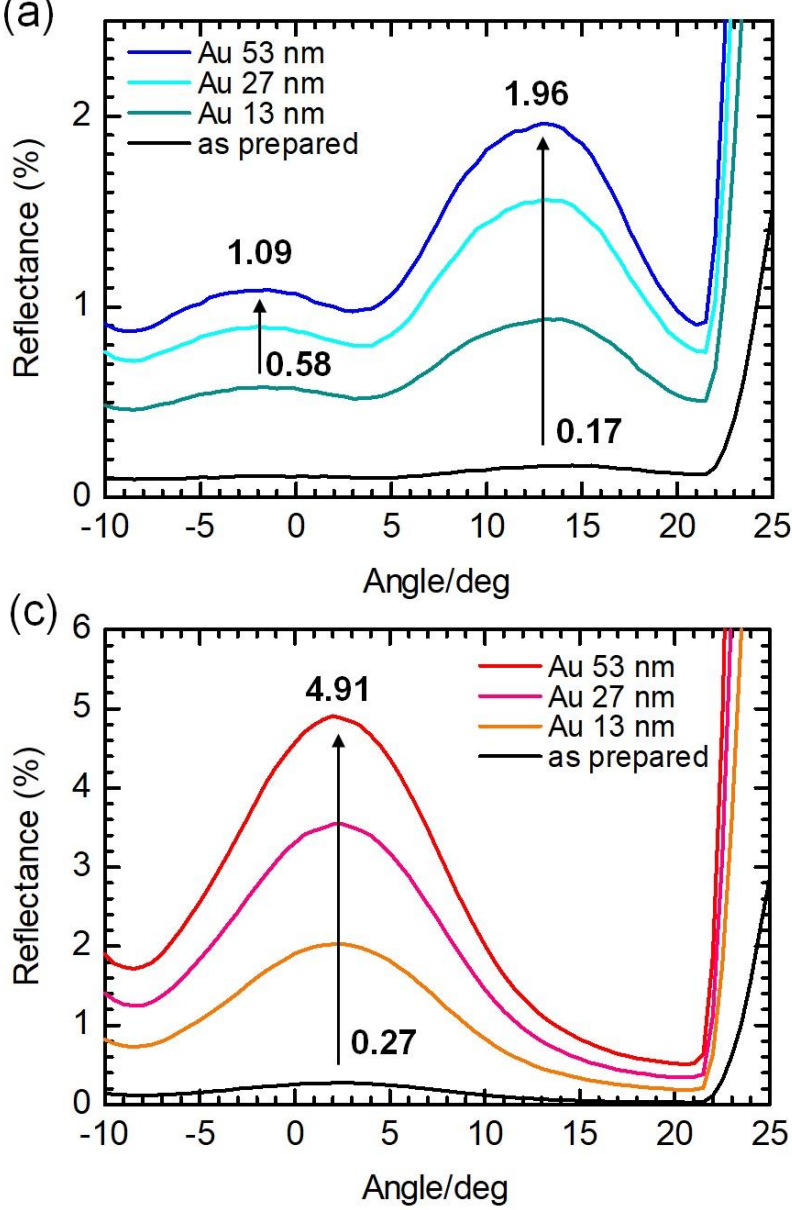

(b)

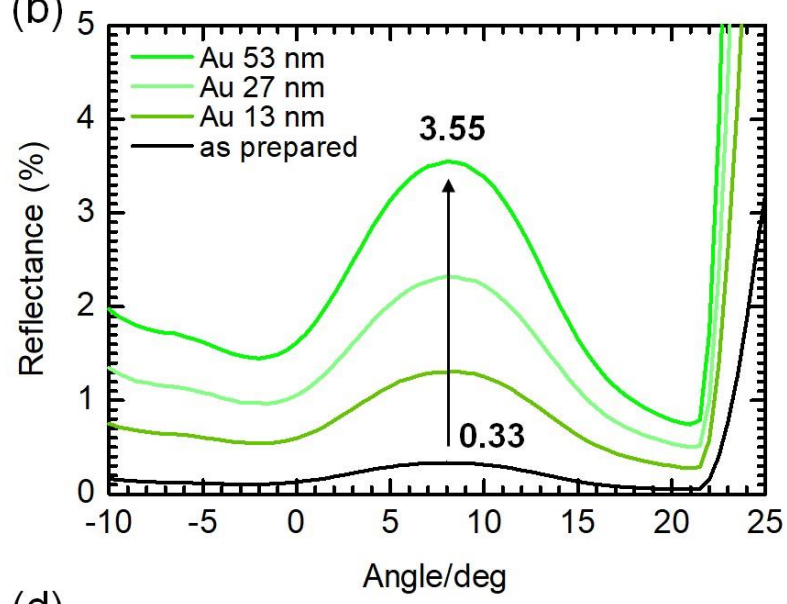

(d)

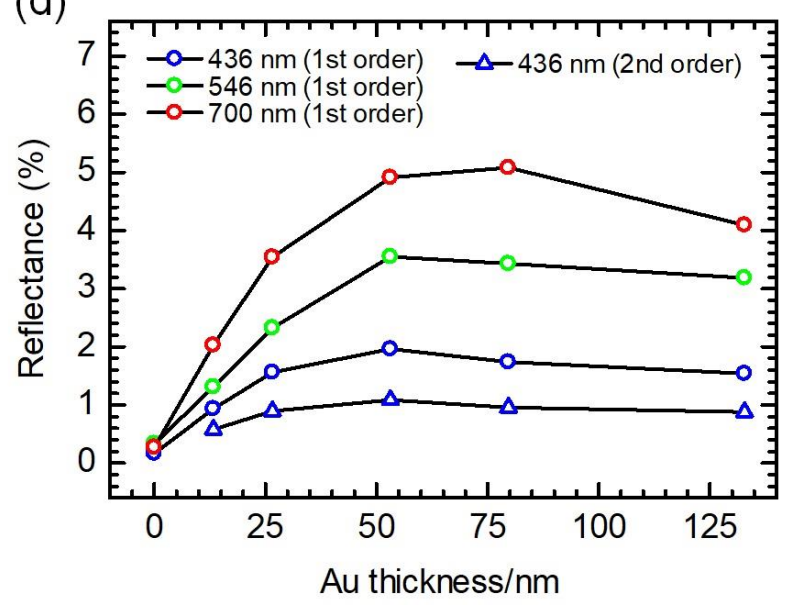

Figure 17. Angle scan measurements of the reflectance on the PEDOT_HPC_66 film at each wavelength: The as-prepared film and Au-coated film (13, 27, and $53 \mathrm{~nm})$ at $436 \mathrm{~nm}$ (a), $546 \mathrm{~nm}$ (b), and $700 \mathrm{~nm}$ (c). Reflectance of Au-coated PEDOT_HPC_66 film as a function of Au thickness (first-order diffraction $(\mathrm{m}=1)$ and second-order diffraction $(\mathrm{m}=2))(\mathrm{d})$. The plots of first-order diffracted light at 436, 546, and $700 \mathrm{~nm}$ are depicted as circles and that of secondorder diffracted light at $436 \mathrm{~nm}$ as triangles.

\section{Conclusions}

PEDOT films having hemisphere-shaped micro-/nanostructures have been electrochemically synthesized in concentrated HPC liquid crystal solution for the first time. Surface observations by SEM and AFM reveal that the PEDOT film exhibits micro-/nano-scale dotted structures on the surface in a large area. The dot diameter can be tuned in the range of ca. 1.1 to $2.0 \mu \mathrm{m}$ by changing the concentration of HPC electrolyte solution. The dots uniform in size and irregular in periodicity show diffraction grating property derived from convex-concave surface at both transmission and reflection modes. Electrochemical redox cycling (doping-dedoping) changes not only the film color, but also the diffracted light color due to the difference of light absorption. The diffracted light angle also depends on the dot size, indicating that the inter-dot distance decreases with the dot diameter. Finally, Au was coated onto the PEDOT_HPC film to 
demonstrate the enhancement of the diffracted light intensity. We found that the reflection intensity of the PEDOT film with Au coating increases more than tenfold. Moreover, secondorder diffracted light behavior of the Au-coated PEDOT_HPC film was observed. This bottomup polymerization technique using HPC as a template could be applied to other conductive polymers for functional surface fabrication and the development of optical materials.

ASSOCIATED CONTENT

\section{Supporting Information}

The Supporting Information is available free of charge on the ACS Publication website at DOI: .

FT-IR (Figure S1); Film thickness (Figure S2); AFM image of PEDOT_HPC_66 film (Figure S3); Cyclic voltammetry (Figure S4); POM images of the PEDOT_HPC film at polymerization time for $10 \mathrm{~min}$ (Figure S5); Angle scan measurements, reflection spectra and CIE color space of the PEDOT_HPC film at incident angle of $45^{\circ}$ and $60^{\circ}$ (Figure S6-S10); Angle scam measurements of the PEDOT_HPC_54-66 film (Figure S11); Deposition rate of Au coating (Figure S12); Reflection type diffraction grating property of the PEDOT_HPC film coated with $\mathrm{Au}$ (Figure S13); Reflectance plots as a function of Au thickness (Figure S14-S16) (PDF)

\section{AUTHOR INFORMATION}

\section{Corresponding Author}

*E-mail: gotoh@ims.tsukuba.ac.jp

\section{Author Contributions}

All authors have given approval to the final version of the manuscript. The authors contributed equally.

\section{Funding Sources}

This research was supported by KAKENHI (No. 17K05985).

\section{Notes}

Any additional relevant notes should be placed here.

\section{ACKNOWLEDGMENT}

This research was supported by KAKENHI (No. 17K05985).

\section{REFERENCES}

(1) Onda, T.; Shibuichi, S.; Satoh, N.; Tsujii, K. Super-Water-Repellent Fractal Surfaces. Langmuir 1996, 12 (9), 2125-2127. https://doi.org/10.1021/la950418o . (2) Barnes, W. L.; Dereux, A.; Ebbesen, T. W. Surface Plasmon Subwavelength Optics. Nature 2003, $424 \quad$ (6950), 824-830. https://doi.org/10.1038/nature01937 . (3) Lee, H.; Lee, B. P.; Messersmith, P. B. A Reversible Wet/Dry Adhesive Inspired by Mussels and Geckos. Nature 2007, 448 (7151), 338-341. https://doi.org/10.1038/nature05968. (4) Huang, Y.-F.; Chattopadhyay, S.; Jen, Y.-J.; Peng, C.-Y.; Liu, T.-A.; Hsu, Y.-K.; Pan, C.-L.; Lo, H.-C.; Hsu, C.-H.; Chang, Y.-H.; Lee, C.-S.; Chen, K.-H.; Chen, L.-C. Improved Broadband 
and Quasi-Omnidirectional Anti-Reflection Properties with Biomimetic Silicon Nanostructures. Nat Nanotechnol 2007, 2 (12), 770-774. https://doi.org/10.1038/nnano.2007.389 . (5) Ma, W.; Yang, C.; Gong, X.; Lee, K.; Heeger, A. Thermally Stable, Efficient Polymer Solar Cells with Nanoscale Control of the Interpenetrating Network Morphology. Adv Funct Mater 2005, 15 (10), 1617-1622. https://doi.org/10.1002/adfm.200500211 . (6) Chen, J.-T.; Hsu, C.-S. Conjugated Polymer Nanostructures for Organic Solar Cell Applications. Polym Chem-uk 2011, 2 (12), 2707-2722. https://doi.org/10.1039/c1py00275a . (7) Dubal, D. P.; Lee, S.; Kim, J.; Kim, W.; Lokhande, C. D. Porous Polypyrrole Clusters Prepared by Electropolymerization for a High Performance Supercapacitor. J Mater Chem 2012, $22 \quad$ (7), 3044-3052. https://doi.org/10.1039/c2jm14470k

(8) Hu, X.; Chen, G.; Wang, X.; Wang, H. Tuning Thermoelectric Performance by Nanostructure Evolution of a Conducting Polymer. J Mater Chem A 2015, 3 (42), 20896-20902. https://doi.org/10.1039/c5ta07381b

(9) Liang, L.; Chen, G.; Guo, C.-Y. Polypyrrole Nanostructures and Their Thermoelectric Performance. Mater Chem Frontiers 2016, 1 (2), 380-386. https://doi.org/10.1039/c6qm00061d . (10) Liu, B.; Soares, P.; Checkles, C.; Zhao, Y.; Yu, G. Three-Dimensional Hierarchical Ternary Nanostructures for High-Performance Li-Ion Battery Anodes. Nano Lett 2013, 13 (7), 34143419. https://doi.org/10.1021/nl401880v

(11) Li, W.; Zhang, Q.; Zheng, G.; Seh, Z.; Yao, H.; Cui, Y. Understanding the Role of Different Conductive Polymers in Improving the Nanostructured Sulfur Cathode Performance. Nano Lett 2013, $13 \quad$ (11), 5534-5540. https://doi.org/10.1021/nl403130h

(12) Shi, Y.; Peng, L.; Ding, Y.; Zhao, Y.; Yu, G. Nanostructured Conductive Polymers for Advanced Energy Storage. Chem Soc Rev 2015, 44 (19), 6684-6696. https://doi.org/10.1039/c5cs00362h

(13) Pan, L.; Qiu, H.; Dou, C.; Li, Y.; Pu, L.; Xu, J.; Shi, Y. Conducting Polymer Nanostructures: Template Synthesis and Applications in Energy Storage. Int J Mol Sci 2010, 11 (7), 2636-2657. https://doi.org/10.3390/ijms11072636

(14) Muro, K.; Watanabe, M.; Tamai, T.; Yazawa, K.; Matsukawa, K. PEDOT/PSS Nanoparticles: Synthesis and Properties. Rsc Adv 2016, 6 (90), 87147-87152. https://doi.org/10.1039/c6ra16829a

(15) Ni, X.; Hu, X.; Zhou, S.; Sun, C.; Bai, X.; Chen, P. Synthesis and Microwave Absorbing Properties of Poly(3,4 - ethylenedioxythiophene) (PEDOT) Microspheres. Polym Advan Technol 2011, $22 \quad$ (5), 532-537. https://doi.org/10.1002/pat.1676

(16) Kelly, T. L.; Yano, K.; Wolf, M. O. Supercapacitive Properties of PEDOT and Carbon Colloidal Microspheres. Acs Appl Mater Inter 2009, 1 (11), 2536-2543. https://doi.org/10.1021/am900575v

(17) Mao, H.; Liu, X.; Chao, D.; Cui, L.; Li, Y.; Zhang, W.; Wang, C. Preparation of Unique PEDOT Nanorods with a Couple of Cuspate Tips by Reverse Interfacial Polymerization and Their Electrocatalytic Application to Detect Nitrite. J Mater Chem 2010, 20 (45), 10277-10284. https://doi.org/10.1039/c0jm01745k

(18) Han, M.; Foulger, S. H. Facile Synthesis of Poly(3,4 - ethylenedioxythiophene) Nanofibers from an Aqueous Surfactant Solution. Small 2006, 2 (10), 1164-1169. https://doi.org/10.1002/smll.200600135

(19) Han, M.; Foulger, S. H. 1-Dimensional Structures of Poly(3,4-Ethylenedioxythiophene) (PEDOT): A Chemical Route to Tubes, Rods, Thimbles, and Belts. Chem Commun 2005, 0 (24), 3092-3094. https://doi.org/10.1039/b504727g 
(20) Zhang, X.; Lee, J.-S.; Lee, G. S.; Cha, D.-K.; Kim, M. J.; Yang, D. J.; Manohar, S. K. Chemical Synthesis of PEDOT Nanotubes. Macromolecules 2006, 39 (2), 470-472. https://doi.org/10.1021/ma051975c

(21) Zhang, Y.; Suslick, K. S. Synthesis of Poly(3,4-Ethylenedioxythiophene) Microspheres by Ultrasonic Spray Polymerization (USPo). Chem Mater 2015, 27 (22), 7559-7563. https://doi.org/10.1021/acs.chemmater.5b03423

(22) Hryniewicz, B. M.; Vidotti, M. PEDOT Nanotubes Electrochemically Synthesized on Flexible Substrates: Enhancement of Supercapacitive and Electrocatalytic Properties. Acs Appl Nano Mater 2018. https://doi.org/10.1021/acsanm.8b00694

(23) Watanabe, T.; Ohira, M.; Koizumi, Y.; Nishiyama, H.; Tomita, I.; Inagi, S. In-Plane Growth of Poly(3,4-Ethylenedioxythiophene) Films on a Substrate Surface by Bipolar Electropolymerization. Acs Macro Lett https://doi.org/10.1021/acsmacrolett.8b00170

(24) Musumeci, C.; Hutchison, J. A.; Samorì, P. Controlling the Morphology of Conductive PEDOT by in Situ Electropolymerization: From Thin Films to Nanowires with Variable Electrical Properties. Nanoscale 2013, 5 (17), 7756-7761. https://doi.org/10.1039/c3nr03093h . (25) Kowalski, D.; Albu, S. P.; Schmuki, P. Current Dependent Formation of PEDOT Inverse Nanotube Arrays. Rsc Adv 2012, 3 (7), 2154-2157. https://doi.org/10.1039/c2ra22222a . (26) Xiao, Y.; Lin, J.-Y.; Tai, S.-Y.; Chou, S.-W.; Yue, G.; Wu, J. Pulse Electropolymerization of High Performance PEDOT/MWCNT Counter Electrodes for Pt-Free Dye -Sensitized Solar Cells. J Mater Chem 2012, 22 (37), 19919-19925. https://doi.org/10.1039/c2jm34425d . (27) Mariani, G.; Wang, Y.; Wong, P.-S.; Lech, A.; Hung, C.-H.; Shapiro, J.; Prikhodko, S.; ElKady, M.; Kaner, R. B.; Huffaker, D. L. Three-Dimensional Core-Shell Hybrid Solar Cells via Controlled in Situ Materials Engineering. Nano Lett 2012, 12 (7), 3581-3586. https://doi.org/10.1021/n1301251q

(28) Döbbelin, M.; Tena - Zaera, R.; Carrasco, P.; Sarasua, J. - R.; Cabañero, G.; Mecerreyes, D. Electrochemical Synthesis of Poly(3,4 - ethylenedioxythiophene) Nanotube Arrays Using ZnO Templates. J Polym Sci Part Polym Chem 2010, 48 (21), 4648-4653. https://doi.org/10.1002/pola.24251

(29) Cho, S.; Lee, S. Fast Electrochemistry of Conductive Polymer Nanotubes: Synthesis, Mechanism, and Application. Accounts Chem Res 2008, 41 (6), 699-707. https://doi.org/10.1021/ar7002094

(30) Xiao, R.; Cho, S.; Liu, R.; Lee, S. Controlled Electrochemical Synthesis of Conductive Polymer Nanotube Structures. J Am Chem Soc 2007, 129 (14), 4483-4489. https://doi.org/10.1021/ja068924v

(31) Taggart, D. K.; Yang, Y.; Kung, S.-C.; McIntire, T. M.; Penner, R. M. Enhanced Thermoelectric Metrics in Ultra-Long Electrodeposited PEDOT Nanowires. Nano Lett 2011, 11 (1), 125-131. https://doi.org/10.1021/nl103003d

(32) Kawabata, K.; Takeguchi, M.; Goto, H. Optical Activity of Heteroaromatic Conjugated Polymer Films Prepared by Asymmetric Electrochemical Polymerization in Cholesteric Liquid Crystals: Structural Function for Chiral Induction. Macromolecules 2013, 46 (6), 2078-2091. https://doi.org/10.1021/ma400302j

(33) Eguchi, N.; Kawabata, K.; Goto, H. Synthesis of Electro-Optically Active Polymer Composite of Poly[2,2'-Bis(3,4-Ethylenedioxythiophene)-Alt-Fluorene]/Hydroxypropyl Cellulose Showing Liquid Crystal Structure. Express Polym Lett 2017, 11 (10), 846-851. 
Eguchi, N.; Goto, H. Electrochemical Synthesis of Poly(3,4-ethylenedioxythiophene) Film Having Dot Structures for Diffraction Grating, ACS Appl. Mater. Int., 2019, 11, 33, 30163-30175.

https://doi.org/10.3144/expresspolymlett.2017.80

(34) Werbowyj, R. S.; Gray, D. G. Liquid Crystalline Structure In Aqueous Hydroxypropyl Cellulose Solutions. Mol Cryst Liq Cryst 1976, 34 (4), 97-103. https://doi.org/10.1080/15421407608083894

(35) Werbowyj, R.; Gray, D. G. Optical Properties of Hydroxypropyl Cellulose Liquid Crystals. I. Cholesteric Pitch and Polymer Concentration. Macromolecules 1984, 17 (8), 1512-1520. https://doi.org/10.1021/ma00138a016

(36) Wan, H.; Li, X.; Zhang, L.; Li, X.; Liu, P.; Jiang, Z.; Yu, Z.-Z. Rapidly Responsive and Flexible Chiral Nematic Cellulose Nanocrystal Composites as Multifunctional Rewritable Photonic Papers with Eco-Friendly Inks. Acs Appl Mater Inter 2018, 10 (6), 5918-5925. https://doi.org/10.1021/acsami.7b19375

(37) Giese, M.; Blusch, L. K.; Khan, M. K.; MacLachlan, M. J. Functional Materials from Cellulose - Derived Liquid - Crystal Templates. Angewandte Chemie Int Ed 2015, 54 (10), 2888-2910. https://doi.org/10.1002/anie.201407141

(38) Zheng, Z.; Li, Y.; Bisoyi, H.; Wang, L.; Bunning, T. J.; Li, Q. Three-Dimensional Control of the Helical Axis of a Chiral Nematic Liquid Crystal by Light. Nature 2016, 531 (7594), 352. https://doi.org/10.1038/nature17141

(39) Ryabchun, A.; Bobrovsky, A.; Stumpe, J.; Shibaev, V. Rotatable Diffraction Gratings Based on Cholesteric Liquid Crystals with Phototunable Helix Pitch. Adv Opt Mater 2015, 3 (9), 12731279. https://doi.org/10.1002/adom.201500159

(40) Kang, S.-W.; Chien, L.-C. Field-Induced and Polymer-Stabilized Two-Dimensional Cholesteric Liquid Crystal Gratings. Appl Phys Lett 2007, 90 (22), 221110. https://doi.org/10.1063/1.2745198

(41) Kawabata, K.; Goto, H. Periodic Structure in a Fluorene-Based Polymer Prepared by Electrochemical Polymerization. Chem Lett 2009, 38 (7), 706-707. https://doi.org/10.1246/cl.2009.706

(42) Sio, L.; Lloyd, P. F.; Tabriyan, N. V.; Bunning, T. J. Hidden Gratings in Holographic Liquid Crystal Polymer Dispersed Liquid Crystal Films. Acs Appl Mater Inter 2018. https://doi.org/10.1021/acsami.8b02821

(43) Liu, Y.; Sun, X. Holographic Polymer-Dispersed Liquid Crystals: Materials, Formation, and Applications. Adv Optoelectron 2008, 2008, 1-52. https://doi.org/10.1155/2008/684349 . (44) Woltman, S. J.; Eakin, J. N.; Crawford, G. P.; Žumer, S. Holographic Diffraction Gratings Using Polymer-Dispersed Ferroelectric Liquid Crystals. Opt Lett 2006, 31 (22), 3273. https://doi.org/10.1364/ol.31.003273

(45) Bunning, T.; Natarajan, L.; Tondiglia, V.; Sutherland, R. HOLOGRAPHIC POLYMERDISPERSED LIQUID CRYSTALS (H-PDLCs)1. Annu Rev Mater Sci 2000, 30 (1), 83-115. https://doi.org/10.1146/annurev.matsci.30.1.83

(46) Caputo, R.; Sio, L.; Veltri, A.; Umeton, C.; Sukhov, A. V. Development of a New Kind of Switchable Holographic Grating Made of Liquid-Crystal Films Separated by Slices of Polymeric Material. Opt Lett 2004, 29 (11), 1261. https://doi.org/10.1364/ol.29.001261 . (47) Meeten, G.; Navard, P. Cholesteric Hydroxypropylcellulose Solutions: Microscopy and Small - angle Light Scattering. J Polym Sci Part B Polym Phys 1988, 26 (2), 413-419. https://doi.org/10.1002/polb.1988.090260214

(48) Donald, A.; Viney, C.; Ritter, A. The Parabolic Focal Conic Texture in a Lyotropic Liquid$\begin{array}{lllllll}\text { Crystalline } & \text { Polymer. } & \text { Liq } & \text { Cryst } & \text { 1986, } & 1 & \text { (3), }\end{array}$ https://doi.org/10.1080/02678298608086516 
(49) Fried, F.; Sixou, P. Lyotropic Mesophases of Hydroxypropylcellulose in Pure Acetic Acid, in Water, and in Mixed Solvents. J Polym Sci Polym Chem Ed 1984, 22 (1), 239-247. https://doi.org/10.1002/pol.1984.170220122 .

(50) Meister, R.; Dumoulin, H.; Hallé, -A M; Pieranski, P. The Anchoring of a Cholesteric Liquid Crystal at the Free Surface. J Phys Ii 1996, 6 (6), 827-844.

https://doi.org/10.1051/jp2:1996214 .

(51) Bouligand, Y. Recherches Sur Les Textures Des États Mésomorphes - 2. — Les Champs Polygonaux Dans Les Cholestériques. J Phys-paris 1972, 33 (7), 715-736.

https://doi.org/10.1051/jphys:01972003307071500 .

(52) Rofouie, P.; Pasini, D.; Rey, A. D. Nanostructured Free Surfaces in Plant-Based Plywoods Driven by Chiral Capillarity. Colloids Interface Sci Commun 2014, 1, $23-26$.

https://doi.org/10.1016/j.colcom.2014.06.003 .

(53) Agez, G.; Bitar, R.; Mitov, M. Color Selectivity Lent to a Cholesteric Liquid Crystal by Monitoring Interface-Induced Deformations. Soft Matter 2011, 7 (6), 2841-2847.

https://doi.org/10.1039/c0sm00950d .

(54) Rasband W. S. ImageJ, U. S. National Institutes of Health, Bethesda, Maryland, USA, https://imagej.nih.gov/is/, 1997-2018.

(55) Palmer, C. A.; Loewen, E. G. Diffraction Grating Handbook; Newport Corporation: New York, 2005; Chapter 2. 
Supporting Information

Electrochemical Synthesis of Poly(3,4-ethylenedioxythiophene) Film Having Dot Structures for Diffraction Grating

Naoto Eguchi, Hiromasa Goto*

Department of Materials Science, Faculty of Pure and Applied Sciences, University of Tsukuba, Tsukuba, Ibaraki 305-8573, Japan.

*Corresponding author: gotoh@ims.tsukuba.ac.jp 


\section{FT-IR spectra}

FT-IR spectra of 3,4-ethyeneldioxythiophene (EDOT), poly(3,4-ethyelnedioxythiophene) (PEDOT) and hydroxypropyl cellulose (HPC) were measured by $\mathrm{KBr}$ method. The spectra are recorded in the range of $400-4000 \mathrm{~cm}^{-1}$ with a resolution of $4 \mathrm{~cm}^{-1}$. Transmittance peak at $890 \mathrm{~cm}^{-1}$ is attributed to $\mathrm{C}-\mathrm{H}$ bending mode connected to the $\alpha$ carbon of thiophene ring. Disappearance of this peak in the polymer spectrum indicates that the EDOT monomers are polymerized and PEDOT is produced. Peaks at 1523,1487 and $1366 \mathrm{~cm}^{-1}$ are attributed to the stretching modes of $\mathrm{C}=\mathrm{C}$ and $\mathrm{C}-\mathrm{C}$ in the thiophene ring. Peaks at 987,848 and $697 \mathrm{~cm}^{-1}$ are attributed to the vibration modes of the C-S. The peaks at 1218 and $1092 \mathrm{~cm}^{-1}$ are attributed to the stretching modes of the ethylenedioxy group. Peaks at $926 \mathrm{~cm}^{-1}$ is attributed to the ethylenedioxy ring deformation mode. $^{1}$

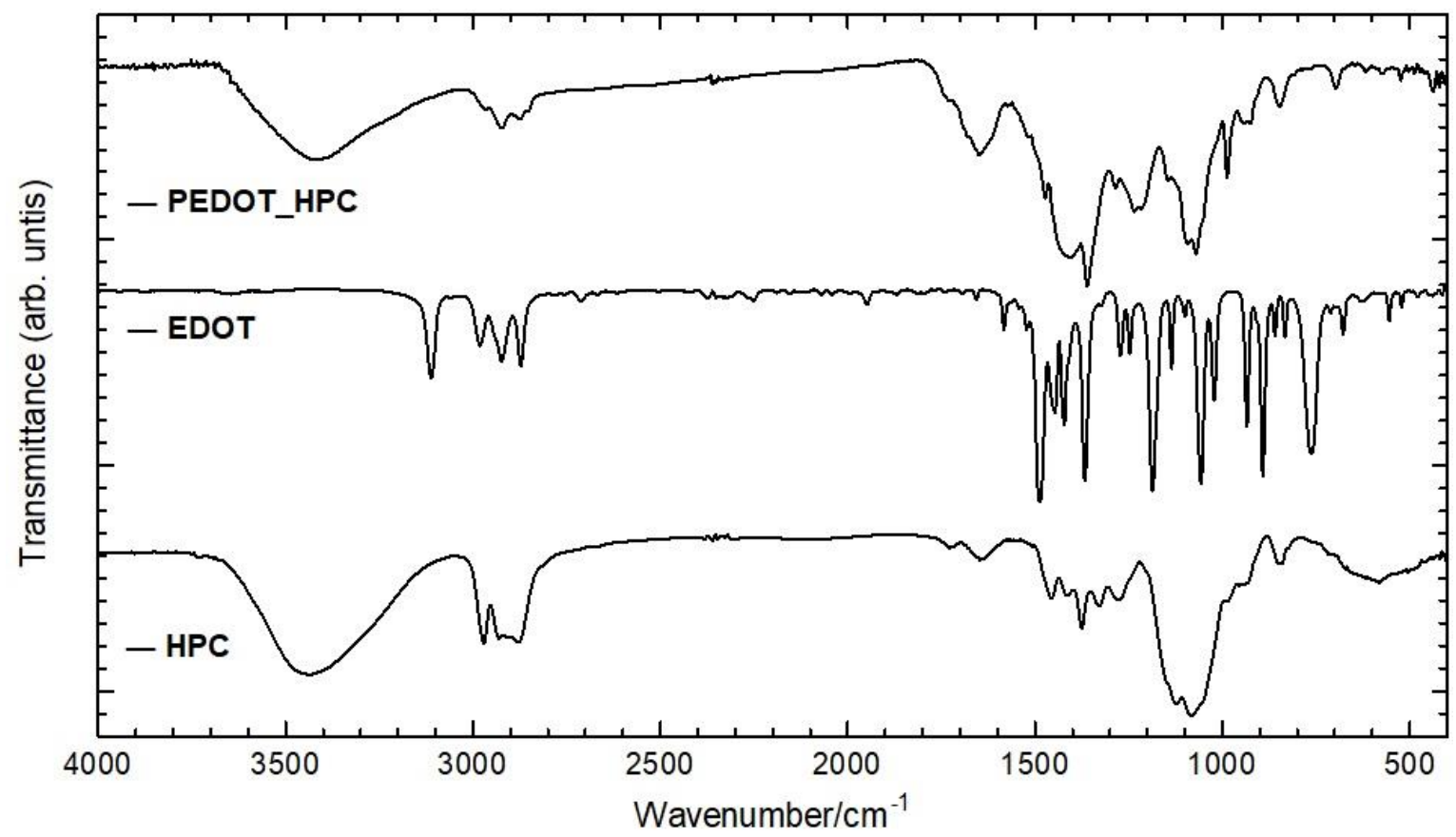

Figure S1. FT-IR spectra of PEDOT_HPC film, EDOT and HPC. 


\section{Film thickness}

(a)
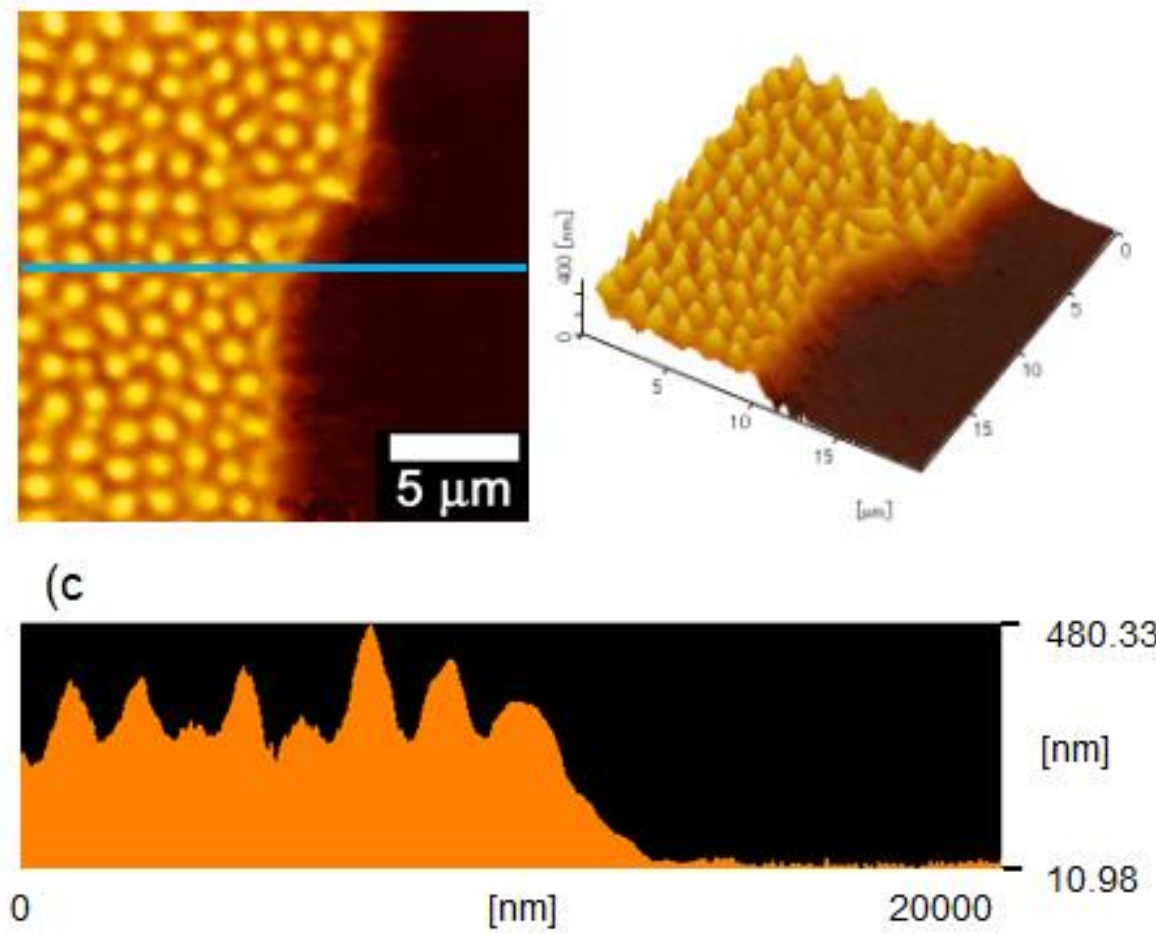

Figure S2. AFM image of PEDOT_HPC film (a). 3D image of AFM image (b). Cross-sectional image along blue line of AFM image (c). 


\section{AFM images of PEDOT_HPC_66 film}

AFM measurements of PEDOT_HPC_66 film prepared by changing applied voltage time from 10 min to 30 min are showed in Figure 6. Cross-section profile at black line in each image are shown in bottom. At the initial state of the electrochemical polymerization, fingerprint texture is observed (a).

When the applied voltage time is $25 \mathrm{~min}$, the low height dot structures begin to be formed (b). As the polymerization time increases, the dot structures grow and become high (c, d).

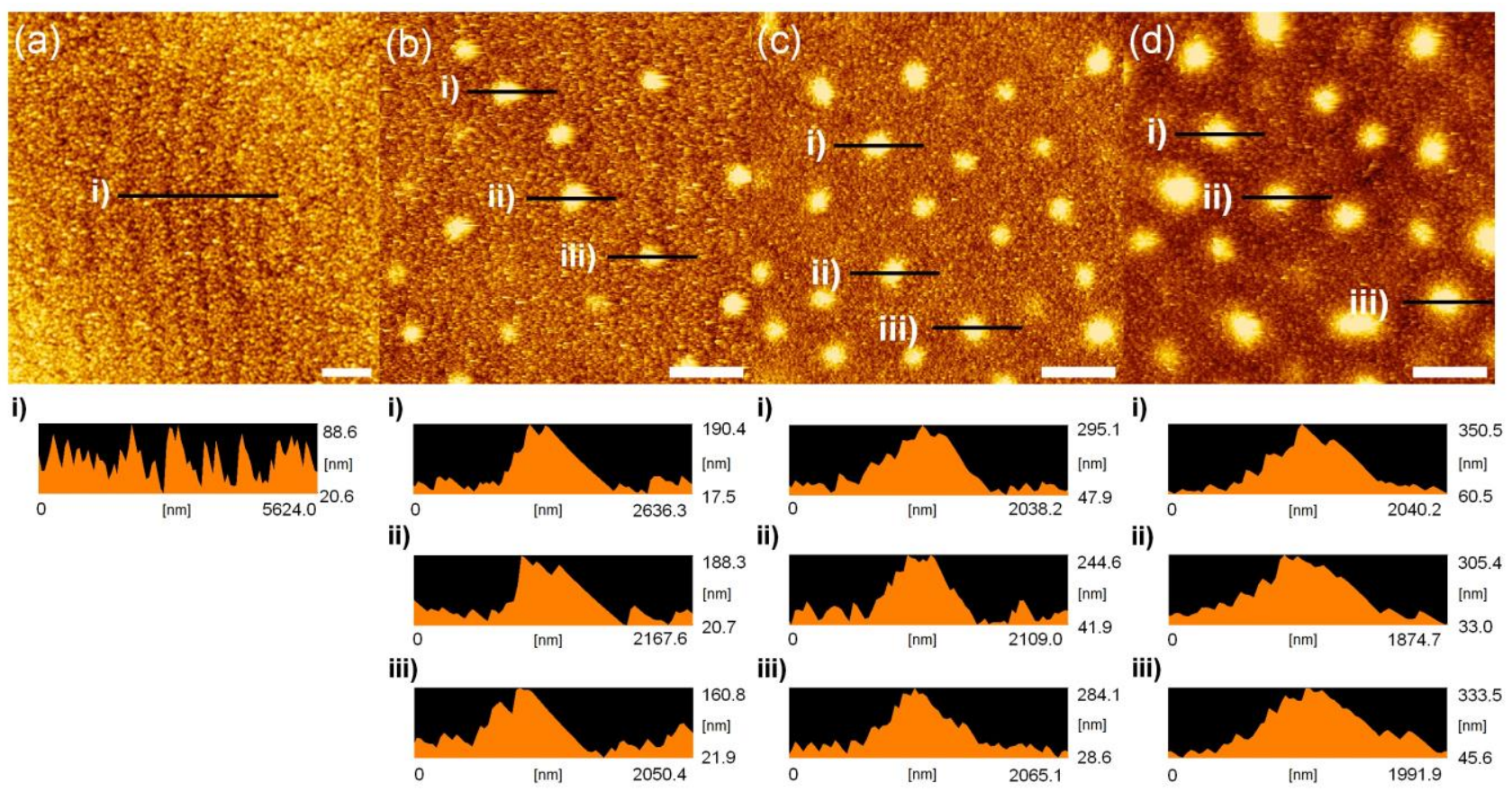

Figure S3. AFM images of the PEDOT_HPC_66 film by changing polymerization time. 10 min (a),

$25 \min (b), 26 \min (c)$ and $30 \mathrm{~min}(\mathrm{~d})$. All scale bars are $2 \mu \mathrm{m}$. 


\section{Cyclic voltammetry}

Cyclic voltammetry was conducted with a $\mu$ AUTOLAB TYPE III (ECO Chemie). ITO glass deposited on a PEDOT_HPC_66 film, $\mathrm{Ag} / \mathrm{AgNO}_{3}$ electrode, and platinum wires were used as a working electrode, reference electrode and counter electrode, respectively. When the scan rates were varied at 10, 20, 30, 40, 50, 60, 70, 80, 90 and $100 \mathrm{mV} / \mathrm{s}$, the oxidation current peak and reduction current peak are gradually increase. Current peak to square root scan rate plot is shown in Figure S4, inset. The linearity of the slope indicates that the oxidation and reduction process of this polymer film is electrochemically reversible.

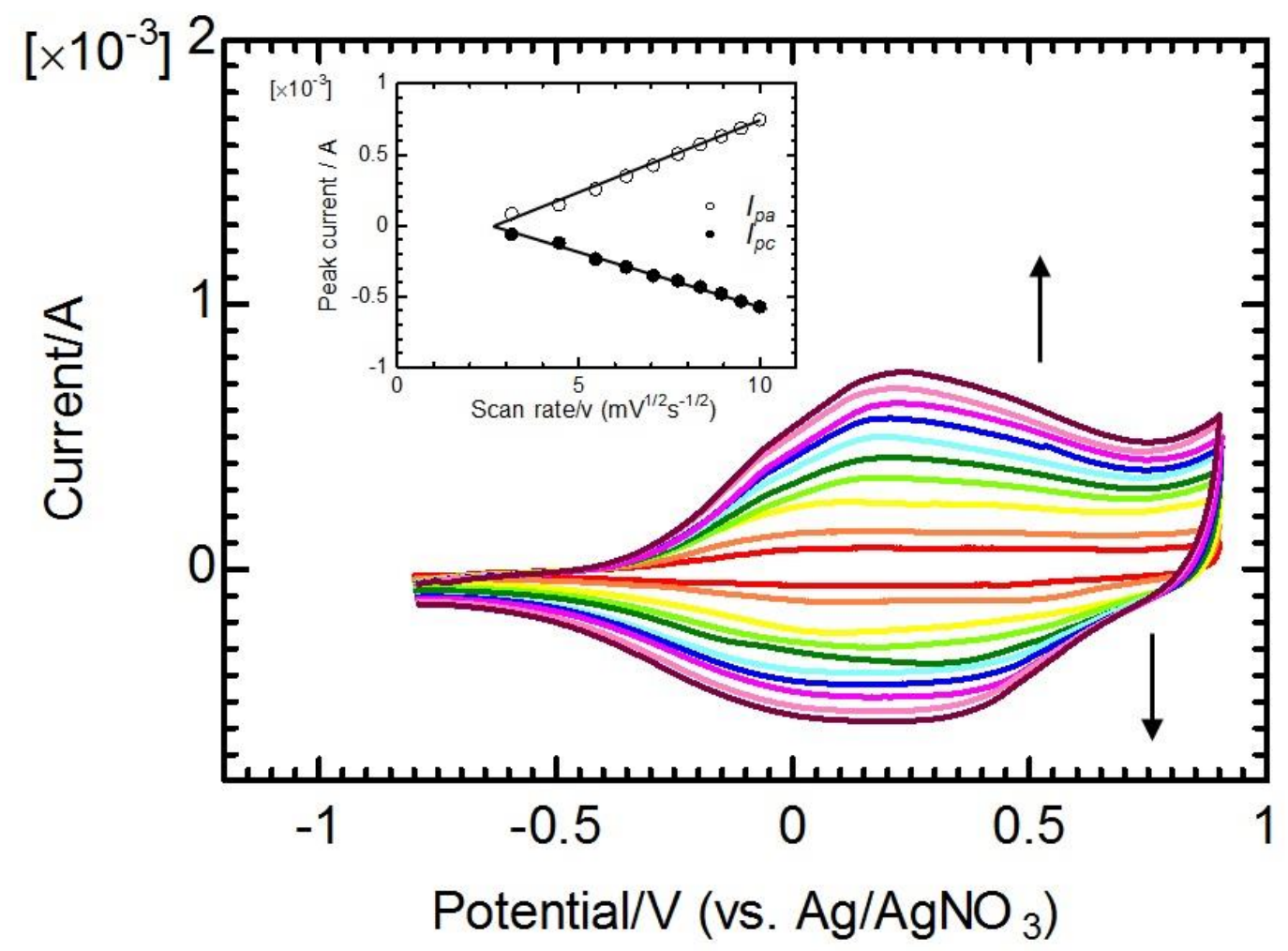

Figure S4. Cyclic voltamogram of PEDOT_HPC film (electrolyte: $0.1 \mathrm{M}$ TBAP/ACN; scan rate: 10 - $100 \mathrm{mV} / \mathrm{s}$ vs. $\mathrm{Ag} / \mathrm{AgNO}_{3}$ ). Cyclic voltammogram of PEDOT_HPC film at various scan rates of 10 to $500 \mathrm{mV} / \mathrm{s}$. TBAP = tetrabutylammonium perchlorate. Insets: plots of redox peak current versus square scan rate of PEDOT_HPC_66 film. 


\section{Helical pitch of electrolyte solutions}

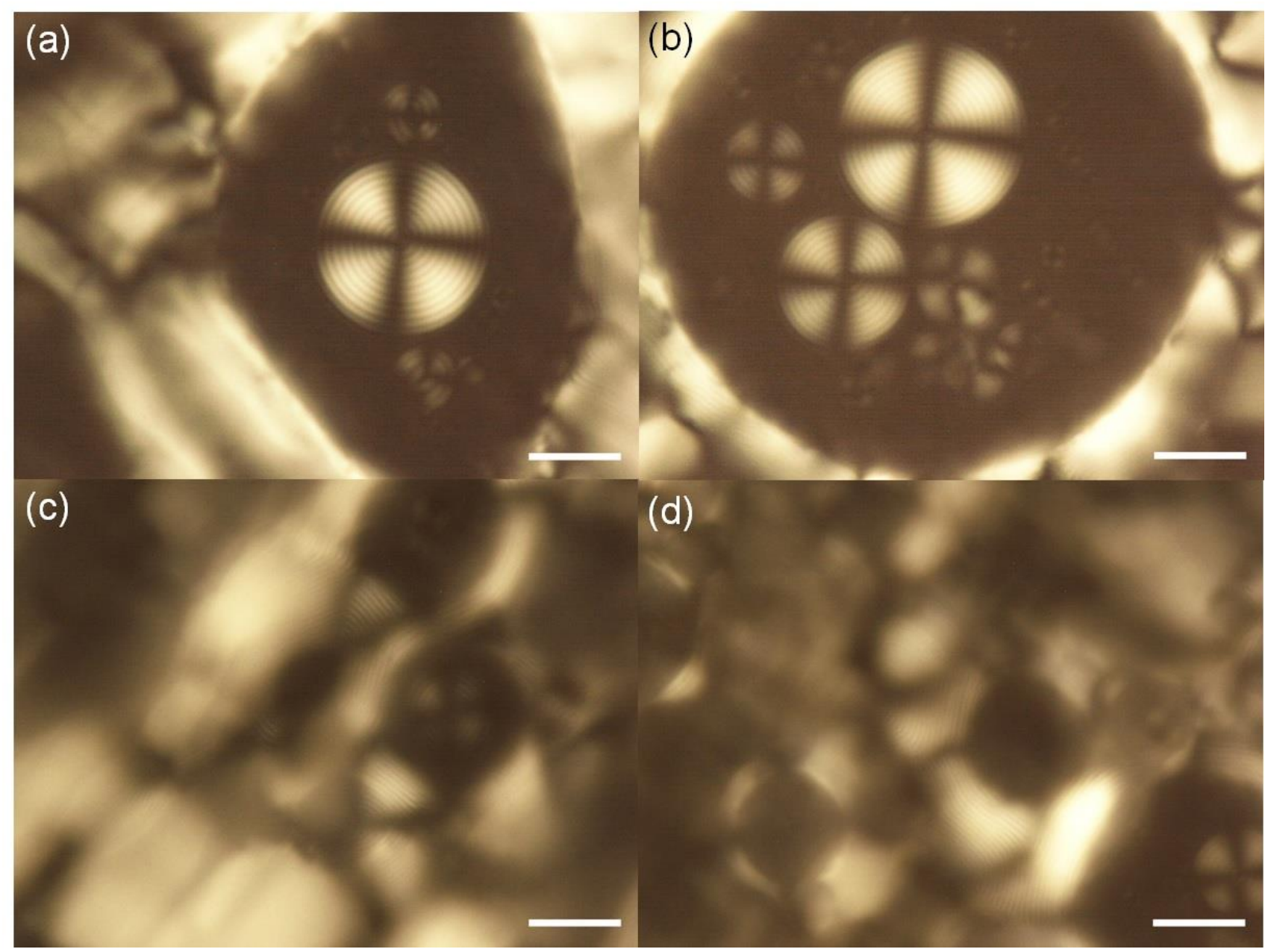

Figure S5. Polarizing optical microscope images of electrolyte solutions. HPC concentration of 54.0 (a), 58.0 (b), 62.0 (c), and 66.0 (d), respectively. Helical pitches were estimated by ImageJ. All scale bars are $10 \mu \mathrm{m}$. 
6. Reflection type diffraction grating property at incident angle of $45^{\circ}$ and $60^{\circ}$

Incident angle $45^{\circ}$
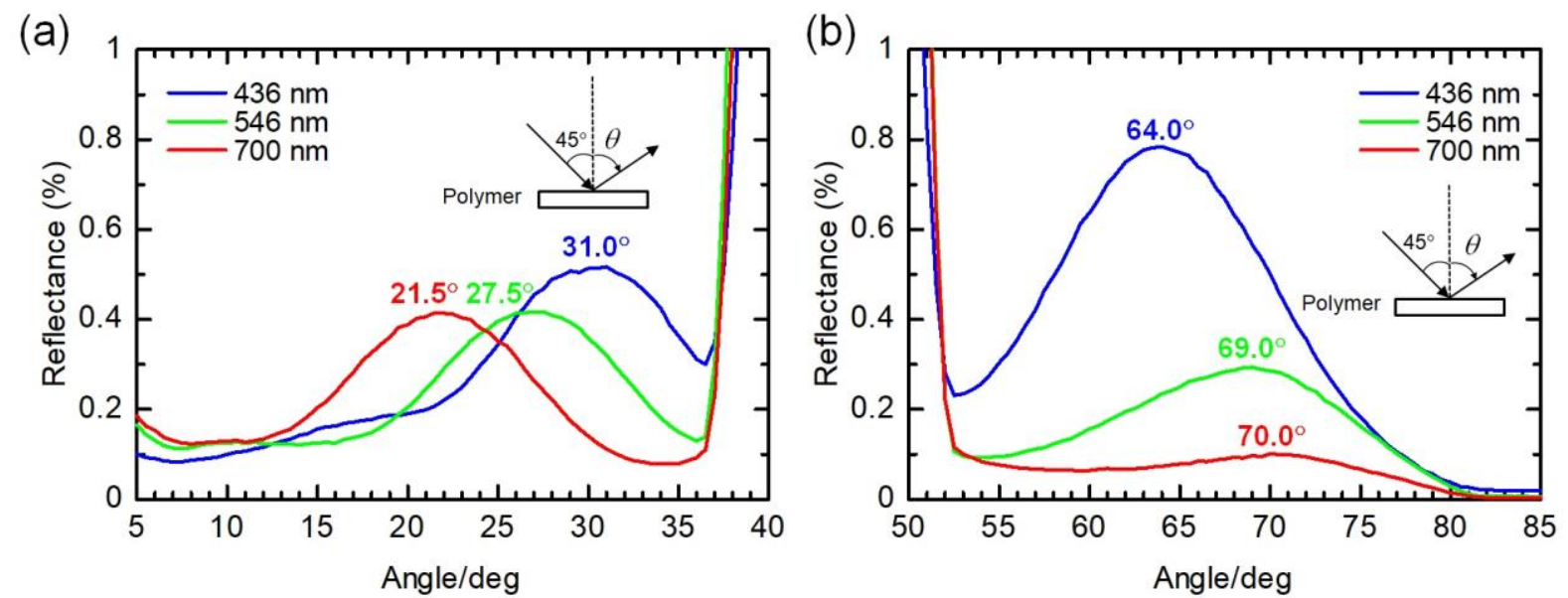

Figure S6. Angle scans measurements of PEDOT_HPC_66 film in the range of $5^{\circ}$ to $40^{\circ}$ (a) and $50^{\circ}$ to $85^{\circ}$ (b).
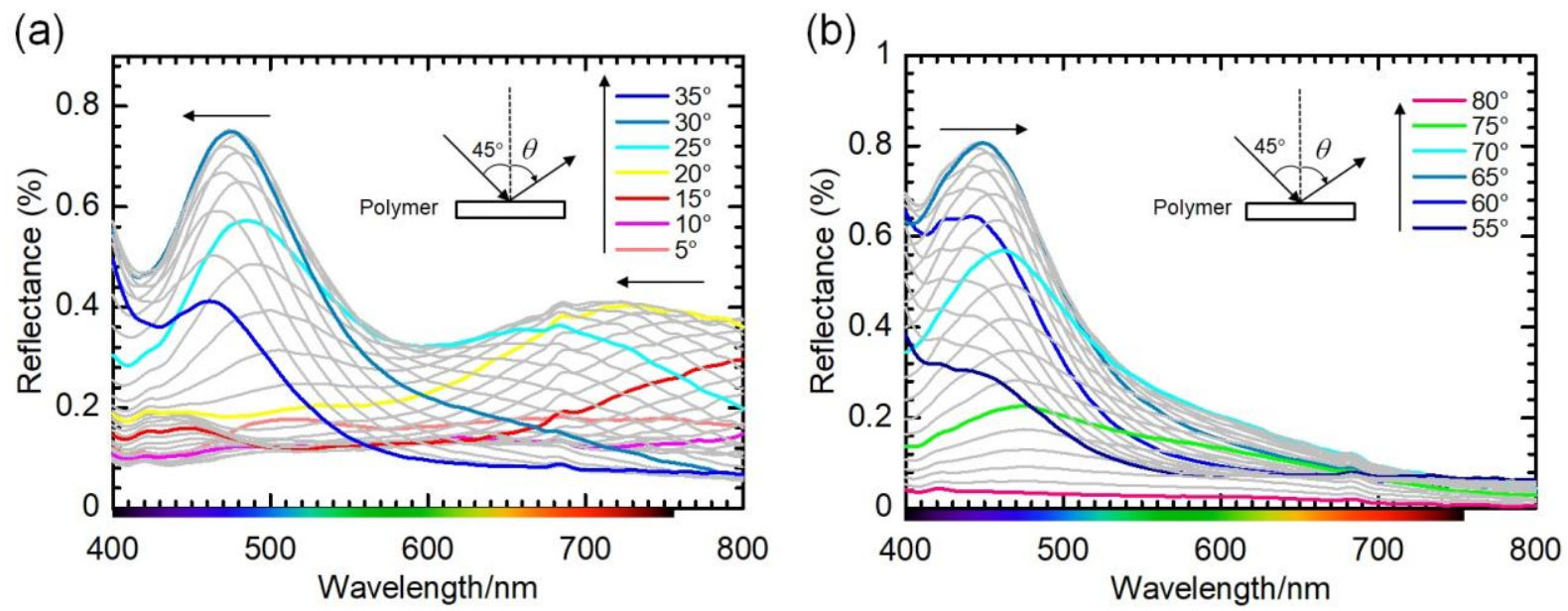

Figure S7. Reflection spectra of PEDOT_HPC_66 film in the range of $5^{\circ}$ to $35^{\circ}$ (a) and $55^{\circ}$ to $80^{\circ}$ (b).

(a)

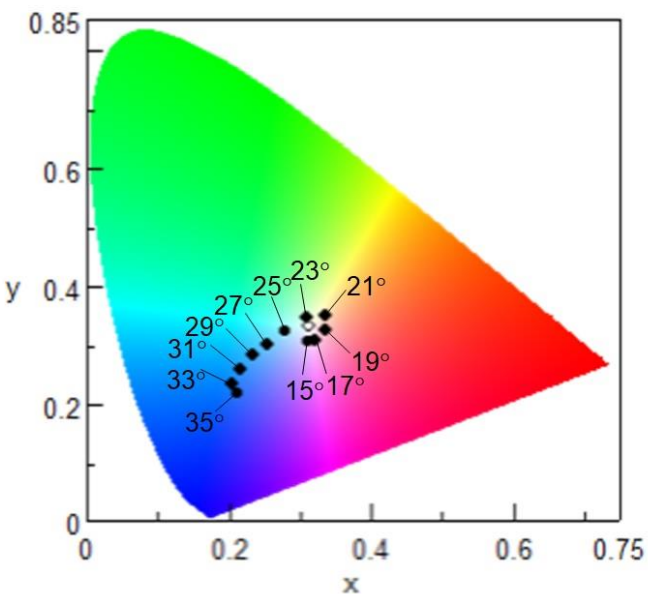

(b)

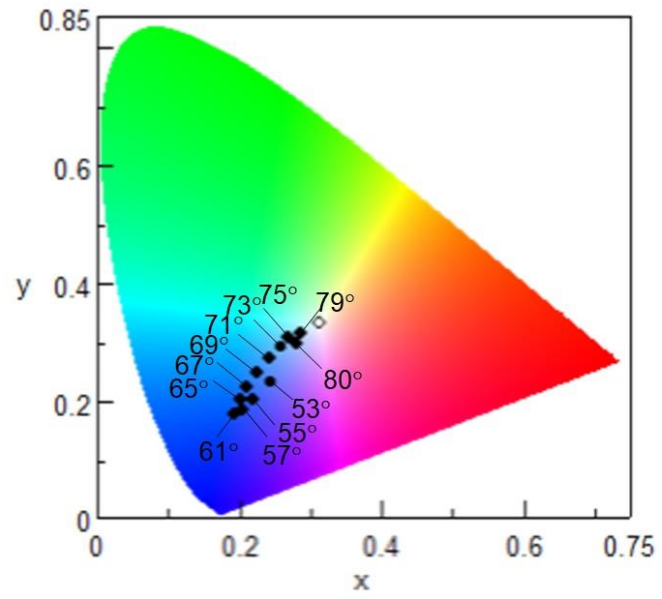

Figure S8. CIE color spectra of PEDOT_HPC_66 in the range of $15^{\circ}$ to $35^{\circ}$ (a) and $53^{\circ}$ to $80^{\circ}$ (b). 
Incident angle $60^{\circ}$

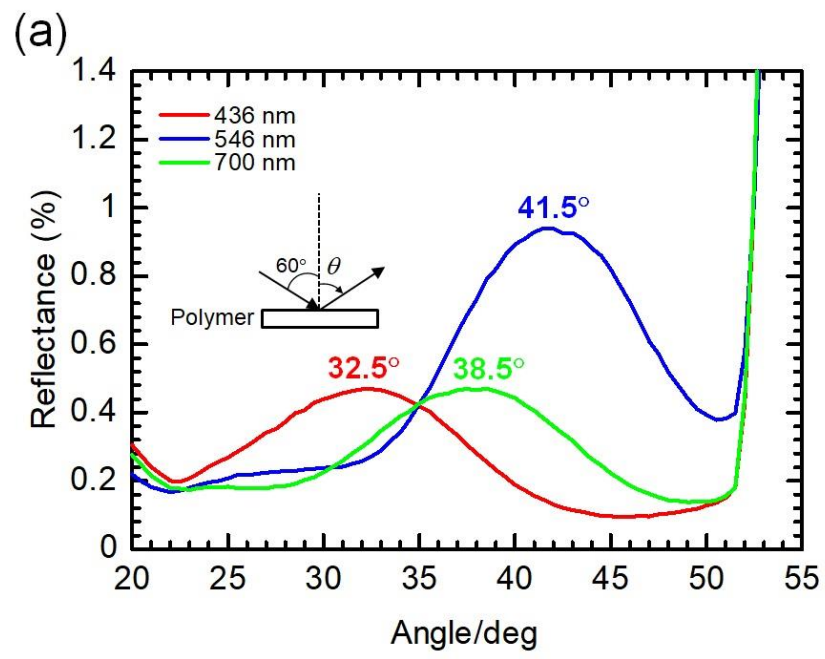

(b)

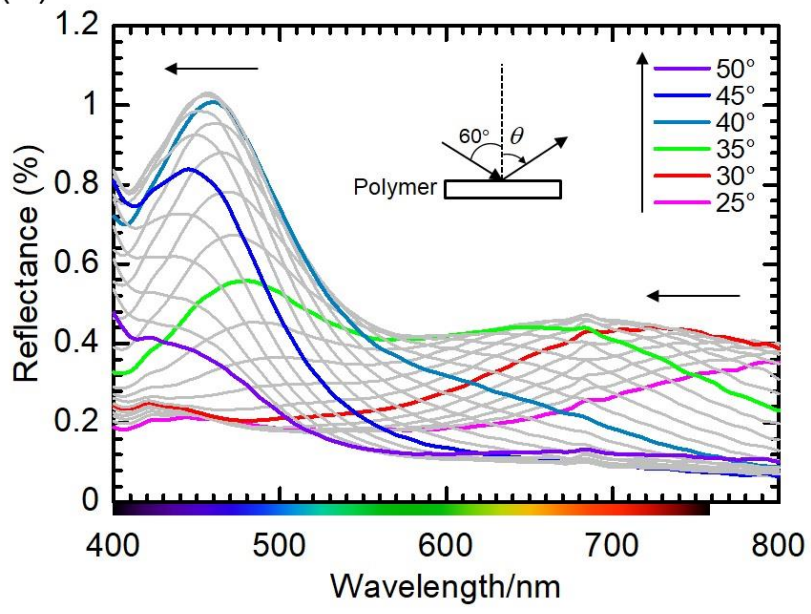

Figure S9. Angle scan measurements of PEDOT_HPC_66 film in the range of $20^{\circ}$ to $55^{\circ}$ (a) and reflection spectra in the range of $25^{\circ}$ to $50^{\circ}$ (b).

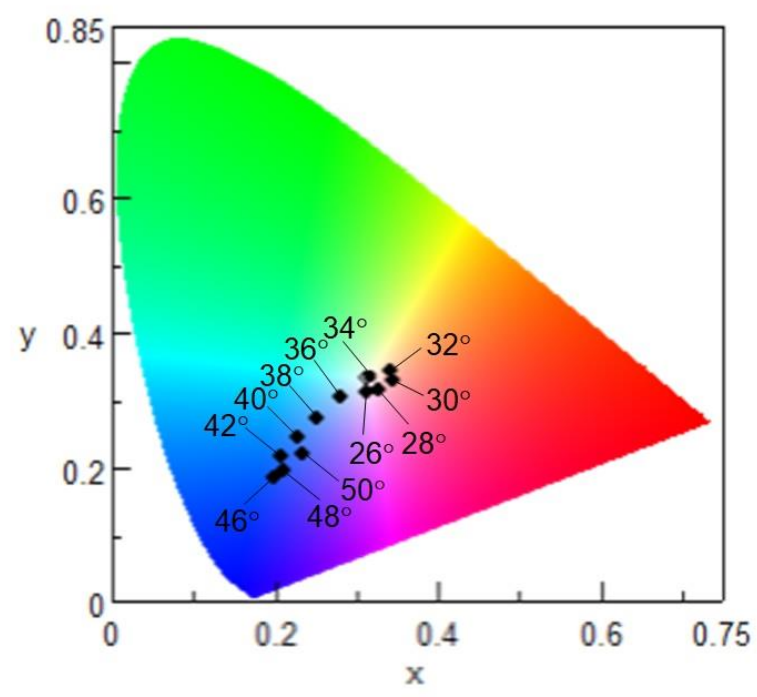

Figure S10. CIE color spectra of PEDOT_HPC_66 in the range of $26^{\circ}$ to $50^{\circ}$. 
7. Angle scan measurements of PEDOT_HPC

(a)

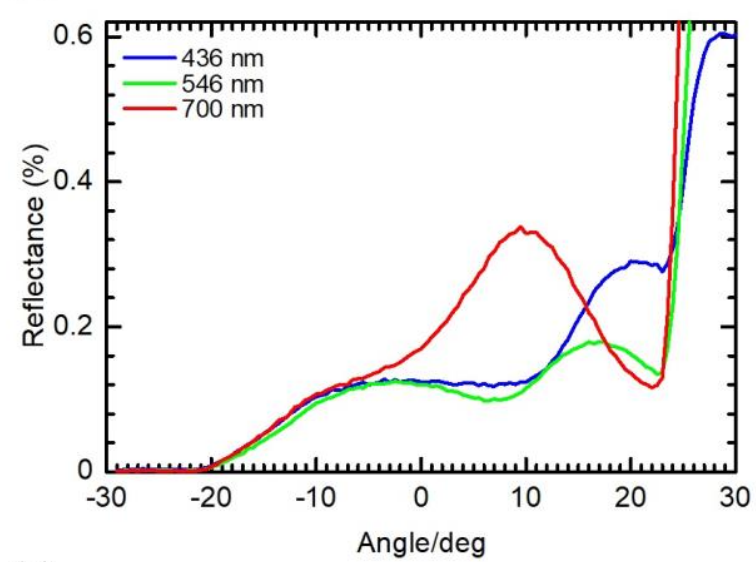

(c)

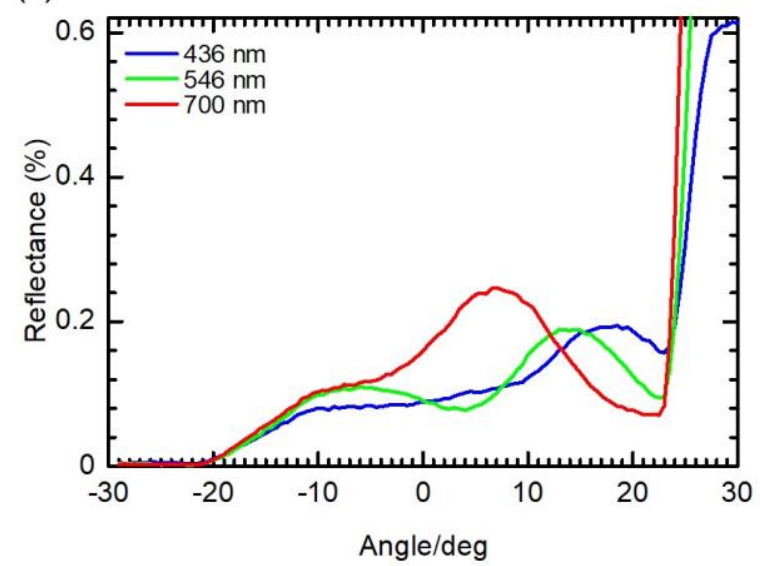

(b)

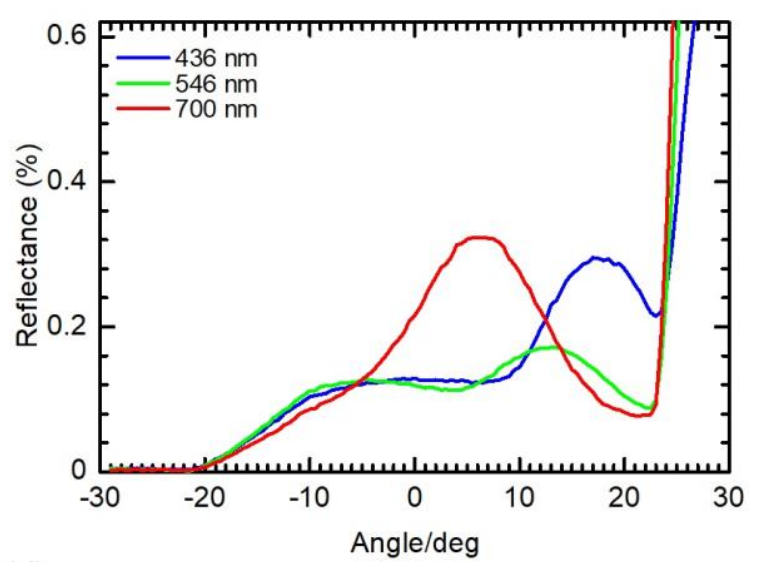

(d)

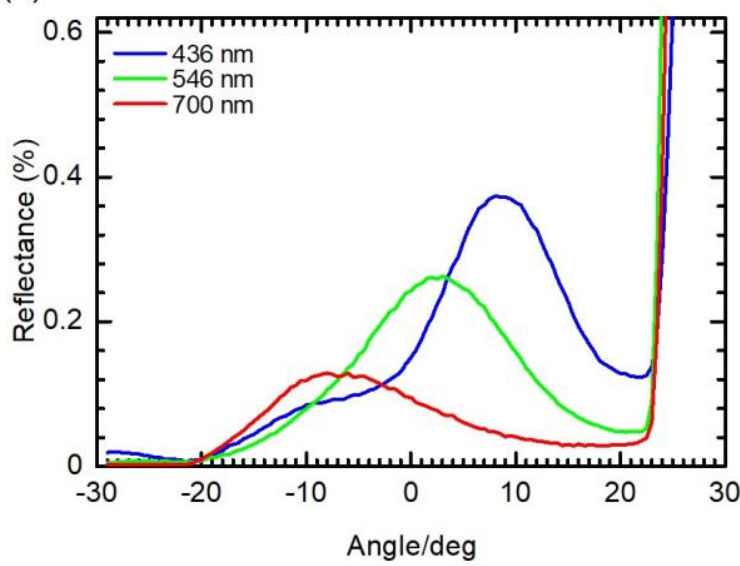

Figure S11. Angle scan measurements of PEDOT_HPC_54 (a), PEDOT_HPC_58 (b), PEDOT_HPC_62 (c) and PEDOT_HPC_66 (d). All measurements were carried out at incident angle of $30^{\circ}$. 


\section{Deposition rate of Au coating}

Coating time to Au thickness plot is showed in Figure S11. Au is coated onto the indium tin oxide (ITO) glass by MSP-1 magnetron sputter. Au thickness was measured by Dektak 3ST (Ulvac). From this result, deposition rate is estimated as $27 \mathrm{~nm} / \mathrm{min}$.

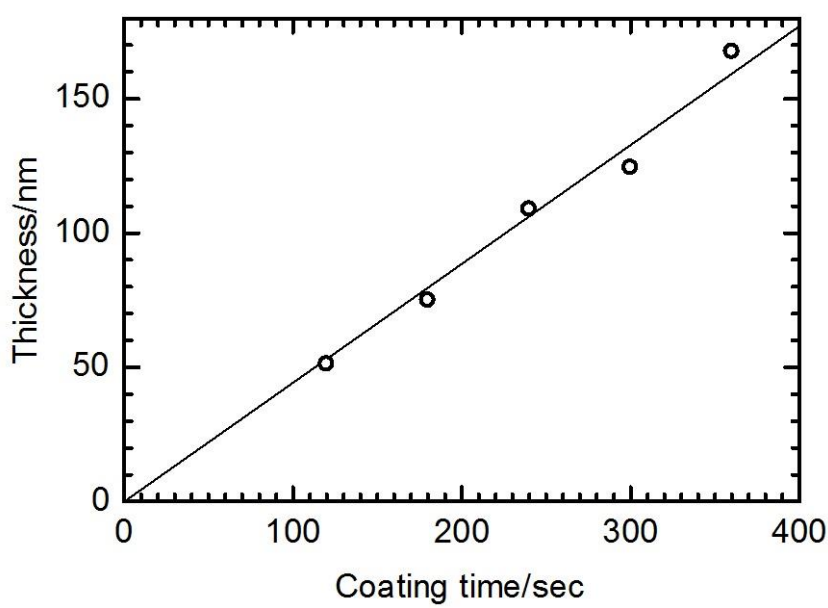

Figure S12. Au thickness plot as a function of coating time.

Table S1. Coating time to Au thickness dependence when Au was sputtered onto the ITO glass for 120 sec to 360 sec.

\begin{tabular}{ll}
\hline Coating time (s) & Au thickness (nm) \\
\hline 120 & 51.21 \\
180 & 74.99 \\
240 & 108.91 \\
300 & 124.40 \\
360 & 167.60 \\
\hline
\end{tabular}




\section{Reflection type diffraction grating property of the PEDOT_HPC film coated with Au}

Figure S13 (a) to (c) shows CIE color spectra of the film with no Au coating, Au coating for 30 seconds (13 $\mathrm{nm})$ and 5 minutes $(133 \mathrm{~nm})$, respectively. The diffracted light color of the film with no Au coating changes from red to blue when the detection angle is scanned from $0^{\circ}$ to $20^{\circ}$. When Au was coated on the PEDOT_HPC film, the diffracted light color changes as shown in Figure S12 (b) and (c). The reflection color slightly shifted to orange and yellow region when the coating time becomes longer. This is may be due to the intrinsic reflection color of $\mathrm{Au}$.

(a)

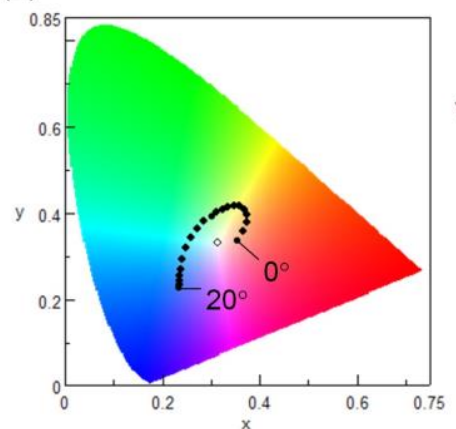

(b)

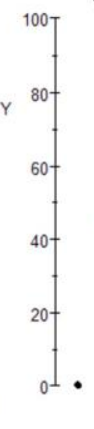

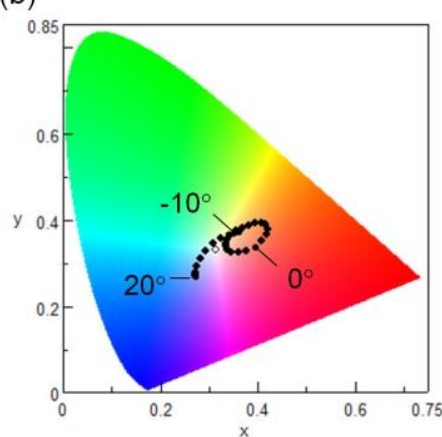

(c)

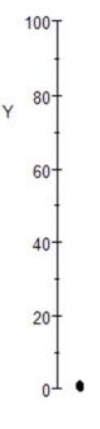

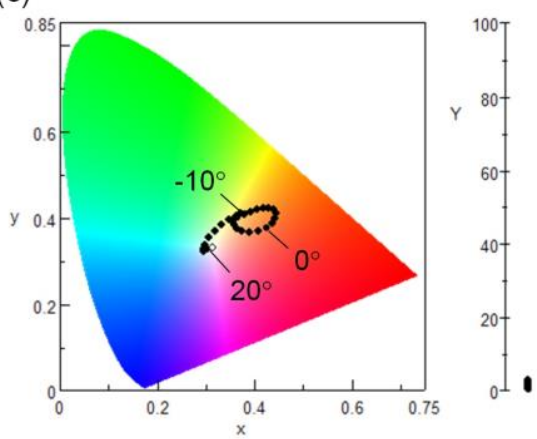

Figure S13. CIE color spectra of PEDOT_HPC_66 film. As prepared state (a) and coated with $13 \mathrm{~nm} \mathrm{Au}$ (b) and $133 \mathrm{~nm}$ (c). 
10. Au thickness to reflectance plot

Incident angle $45^{\circ}$

(a)

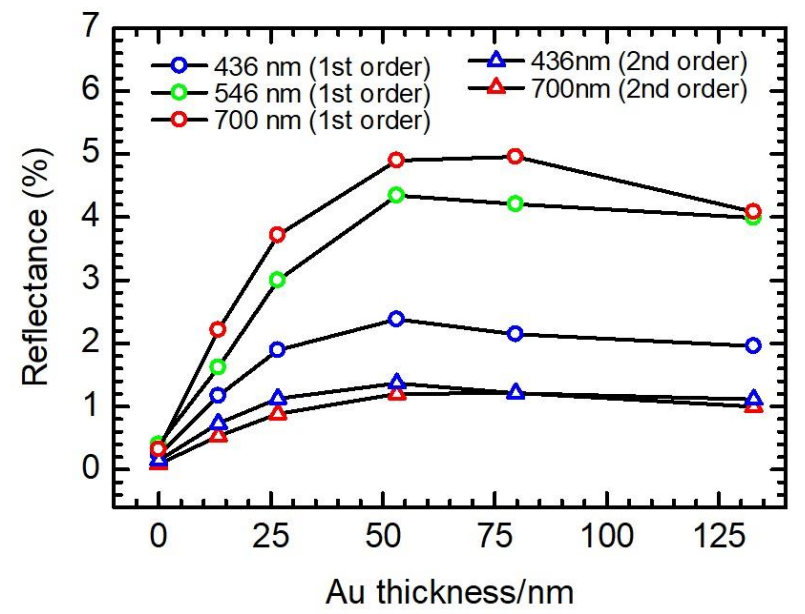

(b)

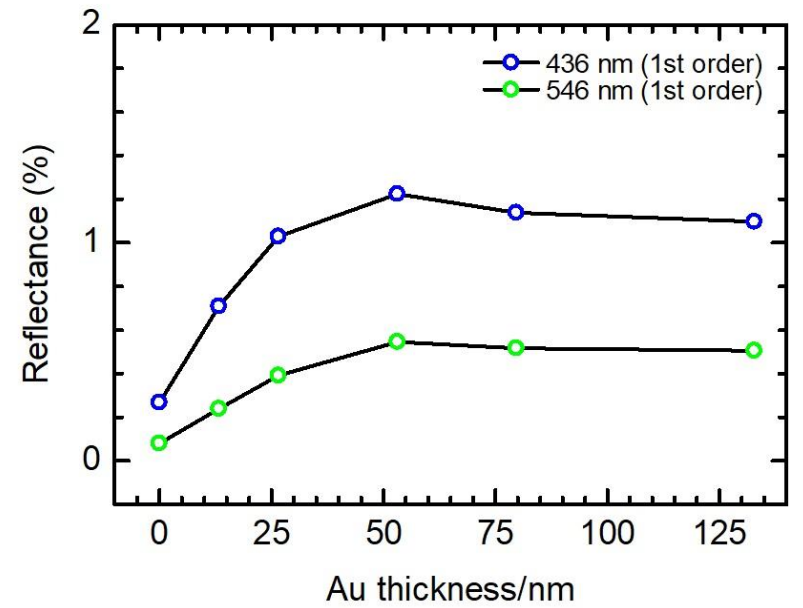

Figure S14. Au thickness to reflectance plot of PEDOT_HPC_66 film at incident angle of $30^{\circ}$. $\quad-1$ order light (a) and +1 order light (b). 
Incident angle $60^{\circ}$

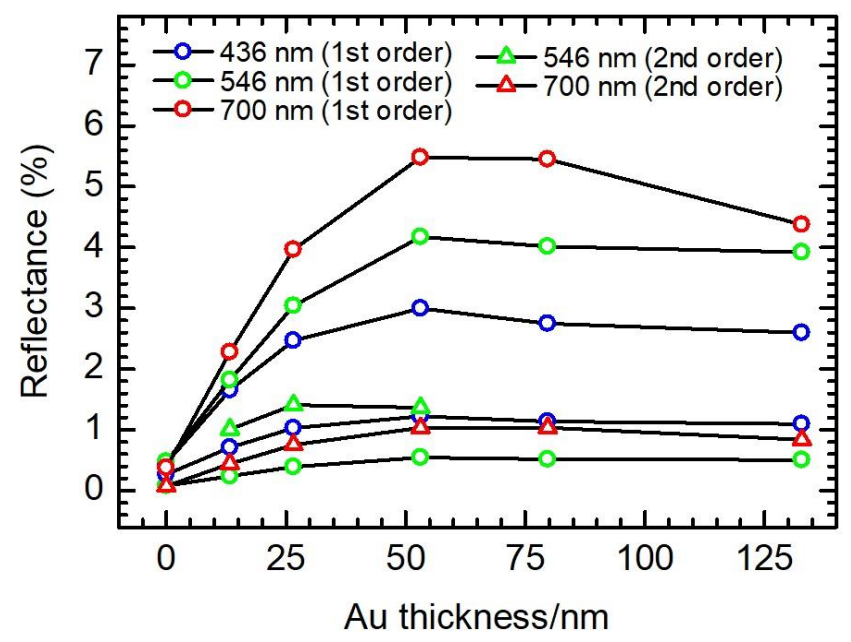

Figure S15. Coating time to reflection intensity (-1 order light) plot of PEDOT_HPC_66 film.

\section{Supporting Reference}

(1) Selvaganesh, V. S.; Mathiyarasu, J.; Phani, K.; Yegnaraman, V. Chemical Synthesis of PEDOT-Au Nanocomposite. Nanoscale Res Lett 2007, 2 (11), 546-549. https://doi.org/10.1007/s11671-007-9100-6 . 